\title{
Influence of the Hopping Technology on the Storage-induced Appearance of Staling Aldehydes in Beer
}

\author{
Jessika De Clippeleer*, Gert De Rouck, Luc De Cooman and Guido Aerts
}

\begin{abstract}
J. Inst. Brew. 116(4), 381-398, 2010

In this paper, the involvement of iso- $\alpha$-acids in the appearance of stale flavour in beer during storage was examined. Flavour instability upon storage, by far the most important quality problem of beer, may be caused by a multitude of reactions, in particular, the degradation of trans-iso- $\alpha$-acids is pivotal. In order to gain improved understanding of the beer ageing process, the behaviour of the stereoisomers of the bitter acids was studied for the first time in pilot beers at particularly high and low proportions of the trans-iso- $\alpha$-acids concentration relative to the cis-iso- $\alpha$ acids concentration. Therefore, pure trans- respectively cis-isomers were required and obtained on a pilot scale by the separation of trans-iso- $\alpha$-acids as $\beta$-cyclodextrin inclusion complexes from a commercial isomerised hop extract, permitting the quantitative dosage to beer in $\mathrm{mg} / \mathrm{L}$ amounts. The relationship between the storage-induced degradation of these iso- $\alpha$-acids in authentic beer samples and the increase in staling aldehydes, especially 2-methylpropanal, 2-methylbutanal and 3-methylbutanal, is the subject of further investigations. A remarkable increase in the relative concentration of $c i s$-iso- $\alpha$-acids was observed in the beers bittered with purified trans-iso- $\alpha$-acids, which may be ascribed to partial conversion, i.e., reverse isomerisation, of trans-iso- $\alpha$-acids via $\alpha$-acids into cis-iso- $\alpha$-acids. In spite of the trans-specific degradation observed during ageing, the decomposition of these bitter acids leading to volatile carbonyl compounds is of minor importance. Aldehyde formation as a function of forced ageing was irrespective of the mode of bittering, emphasising that malt quality and the brewing process itself are probably the most important factors regarding the flavour instability of beer.
\end{abstract}

Key words: beer flavour stability, bitter acids degradation, hopping technology, staling aldehyde formation.

KaHo St.-Lieven, Association K.U. Leuven, Department of Microbial and Molecular Systems (M2S), Leuven Food Science and Nutrition Research Centre (LFoRCe), Laboratory of Enzyme, Fermentation and Brewing Technology, Technology Campus, Gebroeders Desmetstraat 1, B-9000 Gent, Belgium.

*Corresponding author. E-mail: jessika.declippeleer@kahosl.be. Parts of this paper were presented at the 2nd International Symposium for Young Scientists and Technologists in Malting, Brewing and Distilling, May 19-21, 2010 in Freising - Weihenstephan, Germany.

Publication no. G-2011-0110-108

(c) 2010 The Institute of Brewing \& Distilling

\section{INTRODUCTION}

Flavour stability remains one of the main quality criteria for beer, and the urgency to control it is endorsed by the global beer market and its allied need for longer storage times for exported beer. Already from the early stages of storage, after only one or a few months, undesirable modifications of beer flavour are perceived. Ageing of beer involves a decline in beer bitterness, both in quality and intensity, and the development of a sweet taste, but the formation of volatile aldehyde compounds is recognised as one of the major causes of flavour deterioration upon storage $\mathrm{e}^{3,45,51}$. According to the literature, a number of reactions may lead to the formation of off-flavour-active aldehydes in beer, including the (oxidative) degradation of iso- $\alpha$-acids, Strecker degradation of amino acids, autooxidation, photo-oxidation and enzymatic degradation of unsaturated fatty acids, melanoidin-catalysed oxidation of higher alcohols, and aldol condensation of short-chain aldehydes $4,17,18,37,44,45,51$. Notwithstanding many years of research in this field, the flavour chemistry of beer ageing, in particular the relative importance of each of these pathways leading to the formation of aldehydes, is still a controversial issue.

With respect to the formation and/or release of off-flavour active aldehydes in beer upon ageing, this paper focuses on the bitter tasting iso- $\alpha$-acids or isohumulones, the five-membered ring hop derivatives originally not present in hops, but formed by thermal isomerisation from humulones at the wort boiling stage of beer production $^{5,39,49}$. Upon storage in the absence of light, these compounds rapidly undergo degradation in the presence of oxygen species $^{18,24,32}$. This oxidative degradation of iso- $\alpha-$ acids results in a significant decline in beer bitterness intensity and a quality change towards a lingering, more harsh bitterness, accompanied by an astringent note in the taste $^{10,22,27,28,36}$, and has been linked to the development of volatile carbonyl compounds such as 2-methylpropanal, 2-methylbutanal and 3-methylbutanal, associated with staling of beer flavour ${ }^{4,17,18,33,51}$. On the other hand, the oxidative decomposition of iso- $\alpha$-acids during beer ageing has also been linked to the formation of a series of nonvolatile trans-specific cyclic iso- $\alpha$-acid transformation products, exhibiting the aforementioned harsh lingering bitter taste ${ }^{22,27,28}$. Indeed, various researchers have independently revealed that trans-iso- $\alpha$-acids degrade much faster than their cis-counterparts, the latter remaining largely unaltered even after prolonged storage $e^{2,9,10,11,22,24,32,36,52}$. 
Table I. Overview of pilot beers.

\begin{tabular}{|c|c|c|c|c|c|}
\hline Basic brew & Code beer & Hop product & Time of addition & $\begin{array}{c}\text { Cask } \\
\text { volume }\end{array}$ & Aimed bitterness \\
\hline Malt A, & Blank-A & None & None & $50 \mathrm{~L}$ & None \\
\hline \multirow[t]{3}{*}{$2 \mathrm{hL}$} & Iso-A & Commercial isomerised hop extract & Beginning of maturation & $50 \mathrm{~L}$ & $25 \mathrm{mg} / \mathrm{L}$ iso- $\alpha$-acids \\
\hline & Cis-A & Extract containing exclusively $c i s$-iso- $\alpha$-acids ${ }^{\mathrm{a}}$ & Beginning of maturation & $50 \mathrm{~L}$ & $25 \mathrm{mg} / \mathrm{L}$ cis-iso- $\alpha$-acids \\
\hline & Trans-A & Extract containing exclusively trans-iso- $\alpha$-acids ${ }^{\mathrm{a}}$ & Beginning of maturation & $50 \mathrm{~L}$ & $25 \mathrm{mg} / \mathrm{L}$ trans-iso- $\alpha$-acids \\
\hline Malt B, & Blank-B & None & None & $50 \mathrm{~L}$ & None \\
\hline \multirow[t]{3}{*}{$2 \mathrm{hL}$} & Iso-B & Commercial isomerised hop extract & Beginning of maturation & $50 \mathrm{~L}$ & $25 \mathrm{mg} / \mathrm{L}$ iso- $\alpha$-acids \\
\hline & Cis-B & Extract containing exclusively $c i s$-iso- $\alpha$-acids ${ }^{a}$ & Beginning of maturation & $50 \mathrm{~L}$ & $25 \mathrm{mg} / \mathrm{L}$ cis-iso- $\alpha$-acids \\
\hline & Trans-B & Extract containing exclusively trans-iso- $\alpha$-acids ${ }^{\mathrm{a}}$ & Beginning of maturation & $50 \mathrm{~L}$ & $25 \mathrm{mg} / \mathrm{L}$ trans -iso- $\alpha$-acids \\
\hline
\end{tabular}

a These novel hop products were prepared according to our own isolation methodology based on selective removal of trans-isomers from the isomerised hop extract by treatment with $\beta-\mathrm{CD}^{34,35}$.

The epimeric trans- and cis-iso- $\alpha$-acids only differ in their relative configuration of the tertiary hydroxyl at $\mathrm{C}(4)$ and the prenyl side chain at $\mathrm{C}(5)^{49}$. Due to this specific stereochemical orientation, trans-iso- $\alpha$-acids show a region of high electron density and so that they are much more prone to oxidation reactions than are $c i s$-iso- $\alpha$-acids ${ }^{10}$.

In order to gain an improved understanding of the bitter acids degradation process, the present study thoroughly investigated the formation of volatile ageing flavours corresponding to the trans-specific conversion of iso- $\alpha$-acids. By focusing on the marked instability of trans-iso- $\alpha$-acids versus cis-iso- $\alpha$-acids, the relative significance of the pathways leading to the formation of carbonyl compounds was elucidated. Accordingly, the fundamental central question in this study was which compounds are to be regarded as the precursors for the staling volatile aldehyde compounds formed upon beer ageing. Specifically 2-methylpropanal, 2-methylbutanal and 3-methylbutanal are known as both Strecker degradation aldehydes ${ }^{45}$ and as possibly originating from the conversion of hop-derived bitter acids ${ }^{18,33}$. In other words, are these ageing aldehydes derived from the raw material malt and the production process or should they mainly be considered as degradation products of trans-iso- $\alpha$-acids? From this point of view, it was assumed that if hops contribute to the flavour instability of beer, specifically by the conversion of trans-iso- $\alpha$-acids into 2-methylpropanal, 2-methylbutanal and 3-methylbutanal, the development of these volatile off-flavours should be different in authentic beer samples exclusively bittered with cis- respectively transiso- $\alpha$-acids as observed with advanced analysis techniques. To accomplish this, two basic 2 -hL brews, identically produced but derived from two different malt samples, were subdivided and bittered post-fermentation with cis- respectively trans-iso- $\alpha$-acids, separated from a commercial isomerised hop extract by the formation of $\beta$-cyclodextrin inclusion complexes on pilot scale, permitting the quantitative dosage in $\mathrm{mg} / \mathrm{L}$ amounts. Unhopped and with isomerised hop extract post-fermentation bittered beers, also derived from these basic brews, served as references. The increase in concentration of aldehydes was monitored as a function of forced ageing at $30^{\circ} \mathrm{C}$ and related to the beers' bitter acids content and the employed malts.

\section{MATERIALS AND METHODS}

\section{Preparation of pilot beers}

Eight pale lager beers were prepared at the pilot brewery ( 2 hL-scale) of KaHo St.-Lieven (Gent, Belgium).
These eight beers were derived from two basic brews, prepared under identical conditions except for the malt choice (same brewing water, brewing scheme, wort boiling, yeast strain, fermentation, etc.). Brewing was performed as follows: grist: Pilsner malt A or B (40 kg); brewing water: reverse osmosis $(1.4 \mathrm{hL})$ (ratio malt/ brewing water $1 / 3.5)$ with addition of $\mathrm{Ca}^{2+}(40 \mathrm{mg} / \mathrm{L})$; brewing scheme: $\mathrm{pH} 5.6 ; 58^{\circ} \mathrm{C}(10 \mathrm{~min}), 63^{\circ} \mathrm{C}(30 \mathrm{~min})$, $72^{\circ} \mathrm{C}(20 \mathrm{~min})$, and $78^{\circ} \mathrm{C}(1 \mathrm{~min})$; wort filtration with lauter tun; wort boiling: atmospheric boiling for $60 \mathrm{~min}$; wort clarification: whirlpool; original gravity: $12.0^{\circ} \mathrm{P}$; pitching rate: $10^{7}$ cells $/ \mathrm{mL}$; fermentation temperature: $12^{\circ} \mathrm{C}$ (8 days); lagering: 10 days at $0^{\circ} \mathrm{C}$; beer filtration: kieselguhr/cellulose sheets $(1 \mu \mathrm{m})$; packaging: automatic filling with double pre-evacuation of air and $\mathrm{CO}_{2}$ flushing (six-head America monobloc filling equipment, Cimec, Vicenza, Italy) in brown glass bottles $(25 \mathrm{cL})$ closed with conventional crown corks. All experimental beers were bottled with total oxygen levels below $0.05 \mathrm{mg} / \mathrm{L}$.

Both basic 2 hL-brews were boiled and fermented without hop addition. At the transfer fermentation-lagering, the brews were divided into equal parts of $50 \mathrm{~L}$ which remained either unhopped (Blank) or which were bittered post-fermentation with respectively commercial isomerised hop extract (Botanix Ltd., Paddock Wood, UK) (Iso) and preparatively isolated, highly enriched cis- respectively trans-iso- $\alpha$-acids (Cis resp. Trans), separated from a commercial isomerised hop extract with $\beta$-cyclodextrin according to our in-house procedure. An overview of the bittering regimes used for the different experimental beers is presented in Table I. In all cases, a final bitterness equivalent to $25 \mathrm{mg} / \mathrm{L}$ iso- $\alpha$-acids was the goal. The resulting eight fresh pale lager beers are further indicated as beers Blank-A, Iso-A, Cis-A and Trans-A, respectively Blank-B, Iso-B, Cis-B and Trans-B, with A and B referring to the type of malt used.

\section{Beer ageing conditions}

After beer preparation, samples of all bottled beers were force-aged in the dark at $30^{\circ} \mathrm{C}$ in a thermostatically controlled room during 150 days. Every 30 days, samples were stored at $0^{\circ} \mathrm{C}$ to preserve the ageing condition.

\section{Malt samples}

The malt samples used during this study were referred to as A and B. Both malts were well modified and produced on an industrial scale, derived from two different maltings, assuming different processing conditions. Two different barley cultivars were distinguished. 


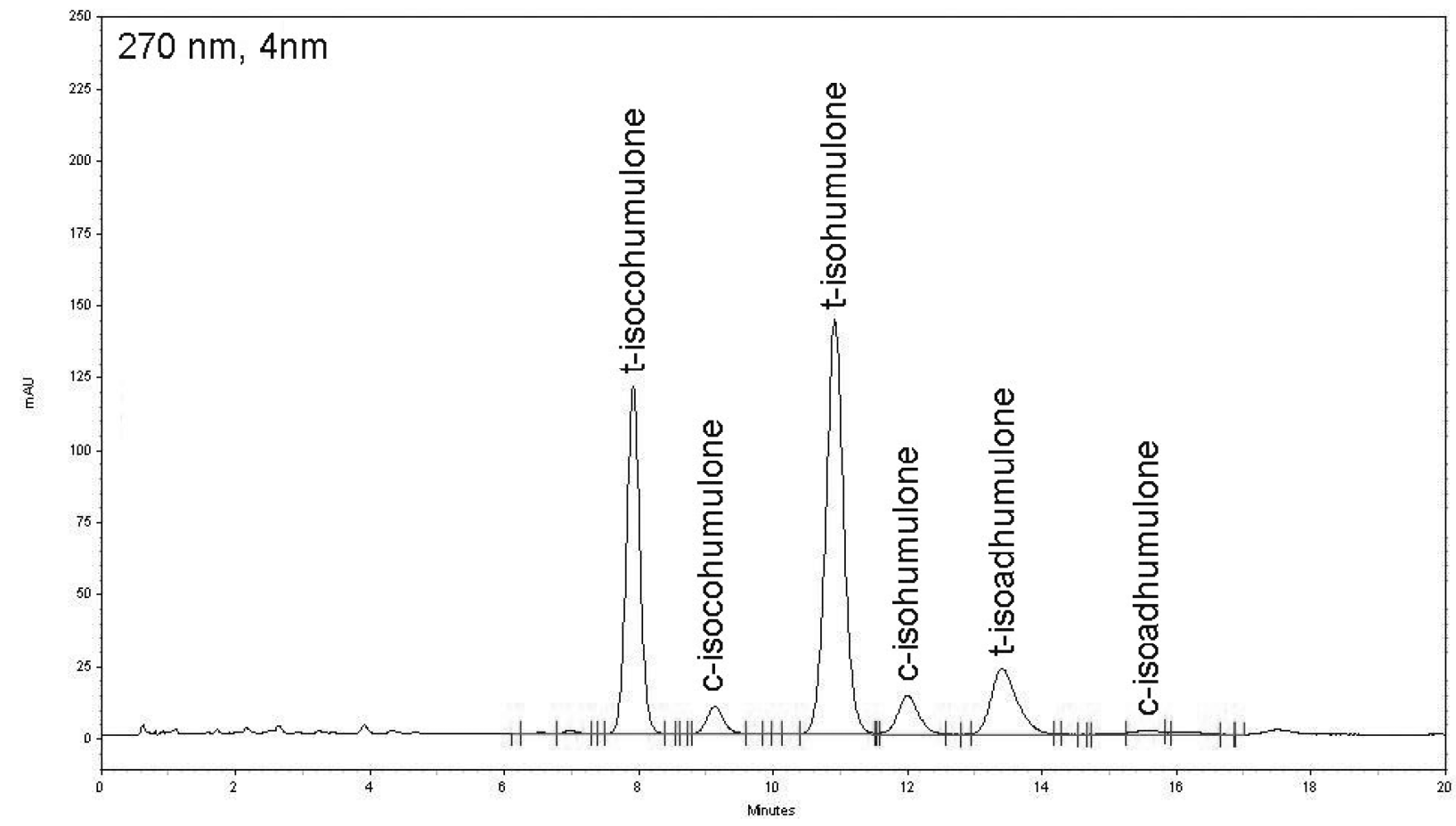

Fig. 1. HPLC separation of the Trans-extract, prepared according to our own isolation methodology based on selective removal of trans-isomers from the isomerised hop extract by treatment with $\beta$-cyclodextrin ${ }^{34,35}$, illustrating the purity of the extract containing $90 \%$ of trans-iso- $\alpha$-acids.

\section{Separation of trans-iso- $\alpha$-acids from cis-iso- $\alpha$ - acids in an isomerised hop extract by the formation of $\beta$-cyclodextrin inclusion complexes}

Separation of trans-iso- $\alpha$-acids from cis-iso- $\alpha$-acids, starting from the commercial isomerised hop extract, was successfully carried out by complex formation of the trans-iso- $\alpha$-acids with $\beta$-cyclodextrin $(\beta$-CD, Acros Organics, Geel, Belgium), according to our in-house procedure based on Khatib et al. ${ }^{34,35}$. This in-house procedure was performed on a pilot scale, permitting the quantitative dosage of trans-, respectively cis-iso- $\alpha$-acids to fermented beer in $\mathrm{mg} / \mathrm{L}$ amounts, and consisted of two successive complex formation steps with a saturated solution of $\beta$ $\mathrm{CD}$ in water $(1.85 \mathrm{~g} / 100 \mathrm{~mL})$. The precipitate from the first complex formation step contained the most enriched trans-isomers, which were recovered from the $\beta$-CD inclusion complexes. The collected first supernatant contained enriched $c i s$-isomers, but in order to obtain a higher purity of the cis-isomers present in this fraction, it was incubated again with $\beta$-CD for a second complex formation step. The most enriched cis-isomers were isolated then from the second supernatant by solid phase extraction. The purity of the cis- and trans-isomer fractions was respectively $98 \%$ cis-iso- $\alpha$-acids and $90 \%$ trans-iso- $\alpha-$ acids, as opposed to the common isomerised hop extracts, which always have an excess of cis-iso- $\alpha$-acids with a typical ratio of $70 \%$ cis-iso- $\alpha$-acids and $30 \%$ trans-iso- $\alpha-$ acids $^{23,49}$. To illustrate the purity of the bittering preparations containing exclusively trans-, respectively $c i s$-iso- $\alpha$ acids, available for post-fermentation addition, the HPLC separation patterns of the Trans- and Cis-extract are depicted in Fig. 1 and 2, respectively.

\section{Liquid-liquid extraction of iso- $\alpha$-acids from beer samples}

Bitter acids were isolated from beer by liquid-liquid extraction, based on the modified IoB method $9.16^{29}$, as described by Jaskula et al. ${ }^{30}$ Degassed beer $(100 \mathrm{~mL})$ was acidified with $5 \mathrm{~mL}$ of $12 \mathrm{M} \mathrm{H}_{3} \mathrm{PO}_{4}$ (Merck, Darmstadt, Germany) and partitioned in a separating funnel with 250 $\mathrm{mL}$ of iso-octane (Acros Organics, Geel, Belgium). After phase separation, the iso-octane layer $(125 \mathrm{~mL})$ was collected, and the solvent was removed under reduced pressure at $30^{\circ} \mathrm{C}$. The residue was redissolved in $1 \mathrm{~mL}$ of ethanol/ $/ \mathrm{H}_{3} \mathrm{PO}_{4}$ (99.75:0.25, vol/vol). Before HPLC analysis, the extract was filtered through a $13-\mathrm{mm}$ syringe filter (0.20- $\mu \mathrm{m}$ PTFE) (Alltech Associates, Deerfield, IL, USA).

\section{HPLC analysis of iso- $\alpha$-acids}

HPLC separations of isolated bitter acids were performed on a Hitachi liquid chromatograph (Merck, Darmstadt, Germany), consisting of a programmable HPLC pump (L-7100) with a quaternary low-pressure gradient system, a diode array detector (L-7450A), an interface module (D-7000), a solvent degasser (L-7612), an autosampler (L-7200) with 100- $\mu \mathrm{L}$ sample loop, a Compaq Deskpro 2000 (Merck HPLC System Manager D-7000 software, version 2.1), and a C18 5- $\mu \mathrm{m}$ column (150 mm $\times 4.6$ mm i.d.; Alltima, Alltech Associates, Deerfield, IL, USA). Chromatographic conditions were as described by De Cooman et al. ${ }^{10}$ Eluent A was milli-Q water adjusted to 


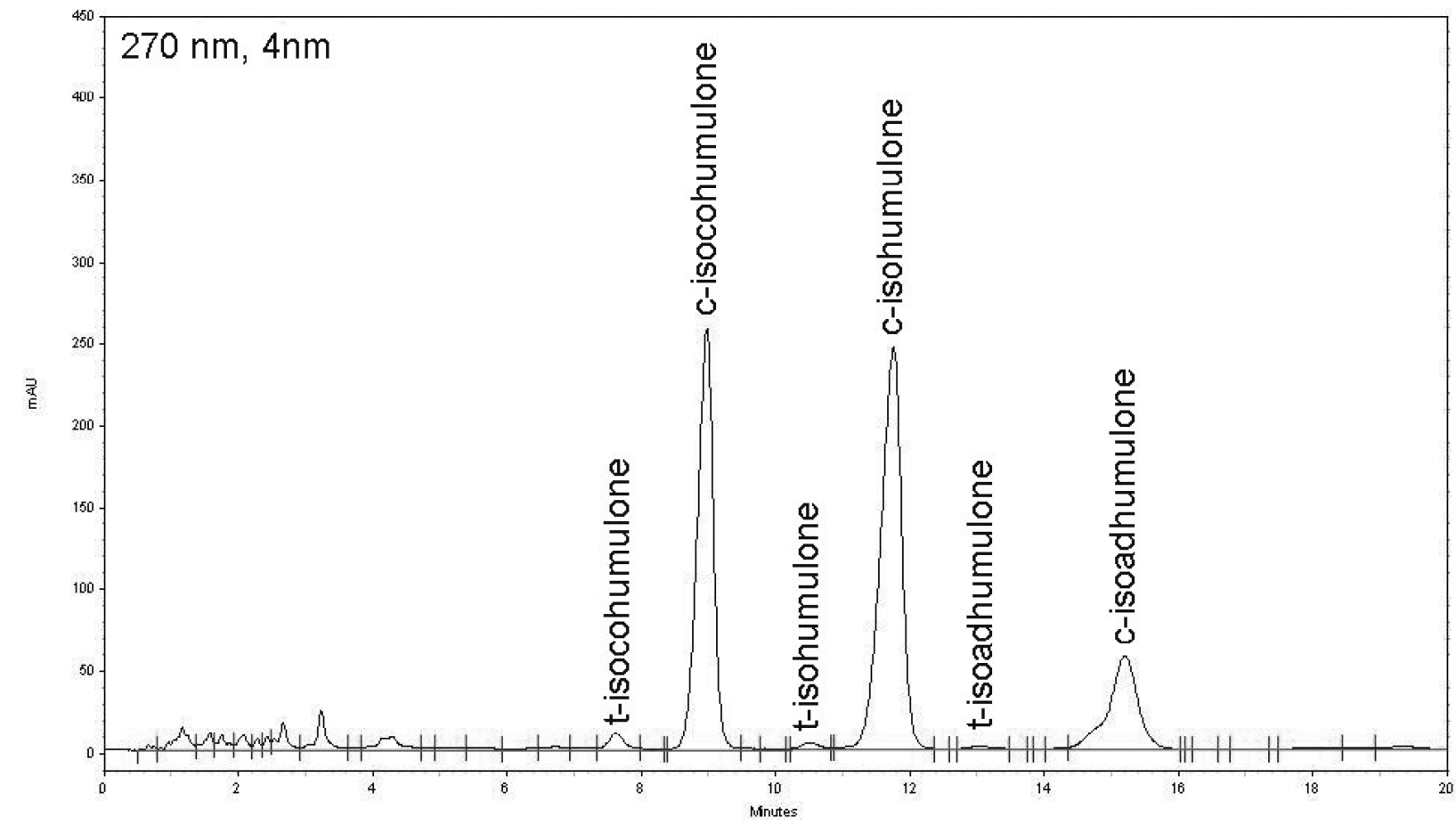

Fig. 2. HPLC separation of the Cis-extract, prepared according to our own isolation methodology based on selective removal of transisomers from the isomerised hop extract by treatment with $\beta$-cyclodextrin ${ }^{34,35}$, illustrating the purity of the extract containing $98 \%$ of cis-iso- $\alpha$-acids.

pH 2.80 with $85 \%$ phosphoric acid (Merck). Eluent B was HPLC-grade acetonitrile (Acros Organics, Geel, Belgium). Isocratic elution was performed using 52\% ( $\mathrm{vol} / \mathrm{vol}$ ) eluent B and $48 \%$ (vol $/ \mathrm{vol}$ ) eluent A. Analysis time was $50 \mathrm{~min}$. Flow rate was $1.8 \mathrm{~mL} \mathrm{~min}^{-1}$. Ambient temperature was used. UV detection was performed at $270 \mathrm{~nm}$ for iso- $\alpha$-acids. A dicyclohexylamine (DCHA)iso- $\alpha$-acids ICS-I1 complex (66.5\% [wt/wt] iso- $\alpha$-acids) (Labor Veritas, Zürich, Switzerland) was used as an external standard for quantification of iso- $\alpha$-acids. Besides quantitative determination of the levels of individual iso$\alpha$-acids, the iso- $\alpha$-acids Trans/Cis-ratio (T/C-ratio) was calculated as follows:

$$
\mathrm{T} / \mathrm{C}=\frac{[\text { trans }- \text { isocohumulone }]+[\text { trans }- \text { isohumulone }]}{[\text { cis }- \text { isocohumulone }]+[\text { cis }- \text { isohumulone }]}
$$

In addition, the iso- $\alpha$-acids Cis/Trans-ratio (C/T-ratio) was calculated as the inverse value of the T/C-ratio. All reported results are the mean values of at least four measurements and calculations.

\section{Headspace SPME of aldehydes from beer samples}

Extraction of marker aldehydes from beer samples was performed by headspace solid phase microextraction (SPME) with on-fibre PFBHA (o-(2,3,4,5,6-pentafluorobenzyl)hydroxylamine, Sigma-Aldrich, St. Louis, MO, USA) derivatisation using a $65 \mu \mathrm{m}$ PDMS-DVB coated fibre (Supelco, Bellefonte, PA, USA). The PFBHA (0.1 $\mathrm{g} / \mathrm{L}$ ) was loaded during $10 \mathrm{~min}$ at $30^{\circ} \mathrm{C}$, after which extraction and derivatisation of the aldehydes from beer was carried out during $30 \mathrm{~min}$.

\section{Headspace SPME of aldehydes from malt samples}

Extraction of marker aldehydes from $\mathrm{CO}_{2}$-milled malt samples $(0.25 \mathrm{~g}$ in $10 \mathrm{~mL}$ water) was performed by headspace SPME with on-fibre PFBHA derivatisation using a $65 \mu \mathrm{m}$ PDMS-DVB coated fibre (Supelco, Bellefonte, PA, USA), as described by De Clippeleer et al. ${ }^{8}$. The PFBHA $(1 \mathrm{~g} / \mathrm{L})$ was loaded during $10 \mathrm{~min}$ at $50^{\circ} \mathrm{C}$, after which extraction and derivatisation of the aldehydes was carried out during $30 \mathrm{~min}$.

\section{GC-MS analysis of aldehydes}

After headspace SPME with on-fibre PFBHA derivatisation, the carbonyl derivatives were analysed according to Vesely et $\mathrm{al}^{50}$, using capillary gas chromatography/mass spectrometry (CGC/MS). The carbonyl derivatives were analysed using a Thermo TraceGC/DSQ II GC/MS system (Interscience, Louvain-la-Neuve, Belgium), equipped with a CTC CombiPAL autosampler, a $\mathrm{S} / \mathrm{SL}$ injector with narrow bore glass inlet liner $(0.5 \mathrm{~mL}$ volume) and a RTX-1 fused silica capillary column ( $40 \mathrm{~m}$ $\times 0.18 \mathrm{~mm}$ i.d., $0.2 \mu \mathrm{m}$ film thickness, Restek, Bellefonte, PA, USA). Helium was used as carrier gas at $0.8 \mathrm{~mL} / \mathrm{min}$. Inlet temperature was set at $250^{\circ} \mathrm{C}$ and injection was carried out in split mode (split ratio 50:1). Oven temperature was kept at $50^{\circ} \mathrm{C}$ for $2 \mathrm{~min}$, then raised to $210^{\circ} \mathrm{C}$ at $6^{\circ} \mathrm{C} / \mathrm{min}$, followed by an increase to $250^{\circ} \mathrm{C}$ at $15^{\circ} \mathrm{C} / \mathrm{min}$ and finally held at $250^{\circ} \mathrm{C}$ for $5 \mathrm{~min}$. The MS transfer line was set at $260^{\circ} \mathrm{C}$. Data were processed with XCalibur $^{\mathrm{TM}}$ (Thermo Electron Corporation, Waltham, MA, USA). All reported results are the mean values of six 


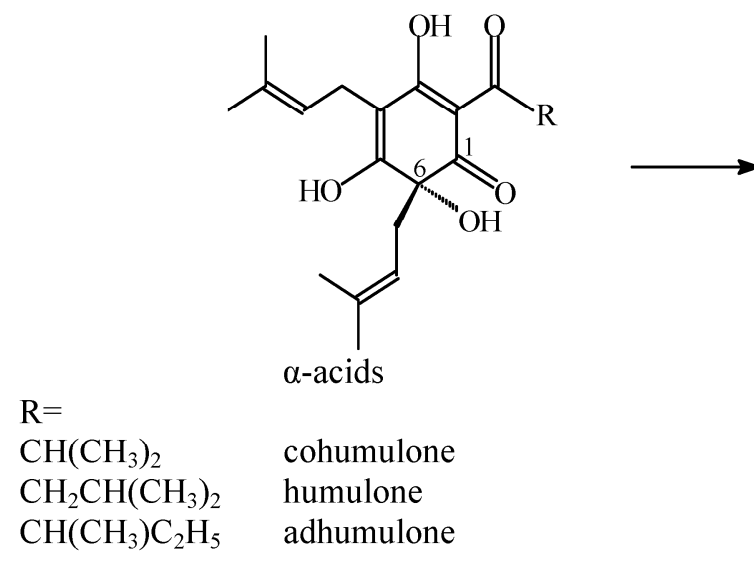

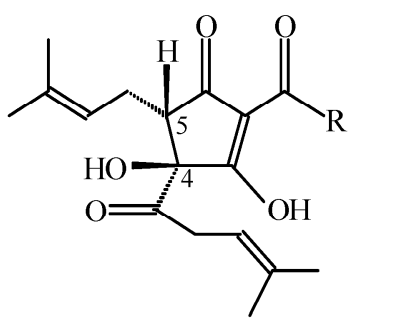

trans-iso- $\alpha$-acids

trans-isocohumulone

trans-isohumulone

trans-isoadhumulone

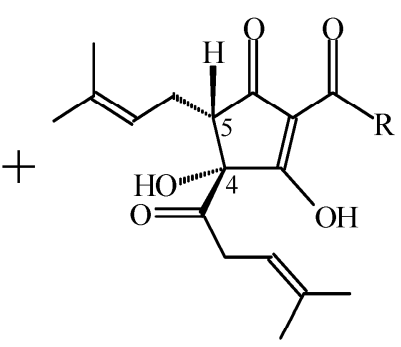

cis-iso- $\alpha$-acids

cis-isocohumulone

cis-isohumulone

cis-isoadhumulone

Fig. 3. Isomerisation of $\alpha$-acids to iso- $\alpha$-acids.

measurements, deriving from two different bottles in the case of beer samples.

\section{RESULTS AND DISCUSSION}

\section{Formation of aldehydes during staling of beer}

The formation of volatile carbonyl compounds containing 6 to $10 \mathrm{C}$-atoms is associated with staling of various food products including alcoholic beverages such as beer $^{3,41,45,51}$. Volatile aldehydes are generally regarded as undesirable due to their low flavour thresholds. As the majority of aldehydes present in wort are reduced to corresponding, less flavour active alcohols, fresh beer contains rather low levels of aldehydes $(\sim 40 \mu \mathrm{g} / \mathrm{L})$ and their presence in fresh beer is mostly imperceptible. During beer ageing, the concentrations of the majority of aldehydes are still far below their individual flavour threshold, but their contribution to the flavour deterioration upon storage is undeniable. The development of stale flavour in beer is therefore attributed to the synergistic effect of a number of carbonyl compounds ${ }^{37}$.

Whereas in the past emphasis was mainly on the determination of trans-2-nonenal since this component contributes to the perception of cardboard flavour at very low concentration levels ${ }^{52,53,55}$, currently a number of marker aldehydes is commonly selected to estimate beer flavour deterioration upon storage $\mathrm{e}^{14,40,41}$. On the basis of multivariate data analysis of the evaluation of commercial pale lager beers in relation to their flavour stability, Malfliet et al. ${ }^{38}$ identified different aldehydes as good markers for beer flavour instability. Some of them are reaction products of Strecker degradation of amino acids (2-methylpropanal, 2-methylbutanal, 3-methylbutanal, methional and phenylacetaldehyde) or result from the oxidation of unsaturated fatty acids (hexanal and trans-2-nonenal). Also the heat-load indicator furfural is definitely included.

\section{Involvement of isohumulones in the formation of volatile aldehydes}

Concerning clarification of the pathways for the production of aldehydes during storage of beer, an attempt was made with the present study to focus on the isohumulones or iso- $\alpha$-acids. Through thermal isomerisation of the hop $\alpha$-acids, six major bitter tasting iso- $\alpha$-acids are pre-

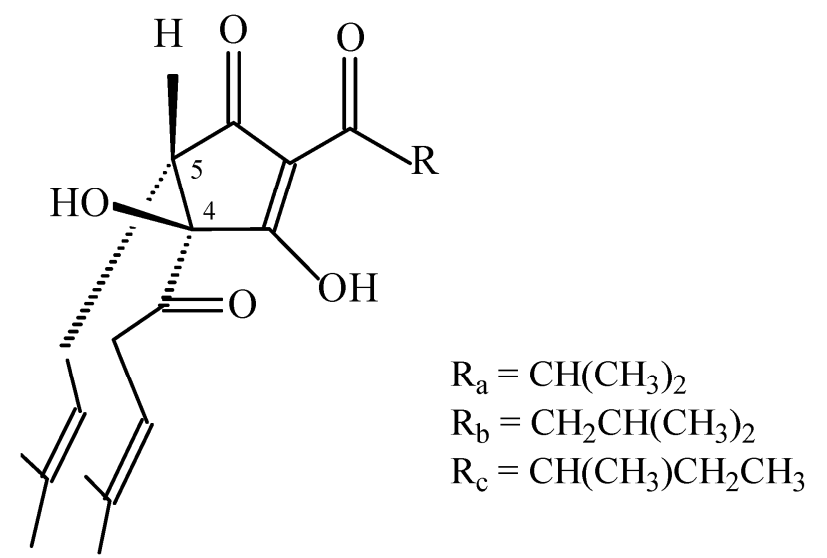

Fig. 4. Configuration of trans-iso- $\alpha$-acids ${ }^{10}$.

sent in beer, i.e., the trans- and cis-isomers of isocohumulone, isohumulone, and isoadhumulone ${ }^{5,49}$ (Fig. 3). As the major bittering principles in beer, these isohumulones play an important role in the beer ageing process in terms of their (oxidative) degradation. Indeed, flavour instability upon storage, by far the most important quality problem of beer, may be caused by a multitude of reactions and the (oxidative) degradation of trans-iso- $\alpha$-acids in particular is pivotal. This differential behaviour of the two types of stereoisomers of the bitter acids has been repeatedly demonstrated during our previous research ${ }^{9,10,11,32,38,43}$ and by various other researchers ${ }^{2,22,24,27,28}$. According to De Cooman et al. ${ }^{10}$, the instability of the trans-isomers can be explained by the different stereochemical arrangement of the isohexenoyl and prenyl side chains at $\mathrm{C}(4)$ and $\mathrm{C}(5)$, respectively (Fig. 4). The proximity of the unsaturated sites in the trans-iso- $\alpha$-acids provides a pool of high electron density, which may initiate auto-oxidation, either by direct reaction involving the double bonds or by allylic hydrogen abstraction from the doubly activated $\alpha$-carbon of the isohexenoyl side chain at C(4). Radical chemistry rapidly ensues, leading to a multitude of oxidation products.

Various authors have suggested chemical structures of putative degradation products of iso- $\alpha$-acids ${ }^{18,19,20,21,22,25,26,27,28,33}$. Non-volatile trans-specific cyclic iso- $\alpha$-acid transformation products, generated exclusively from trans-iso- $\alpha$-ac- 

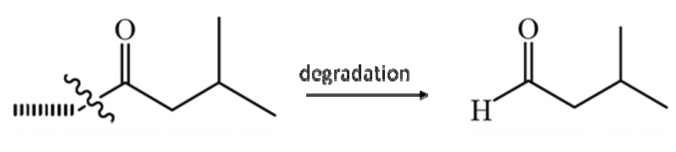

n-<smiles>CC(C)C(=O)C(C)C</smiles>

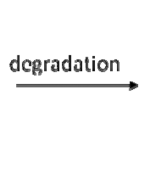<smiles>CC(C)C=O</smiles>

3-methylbutanal

2-methylpropanal
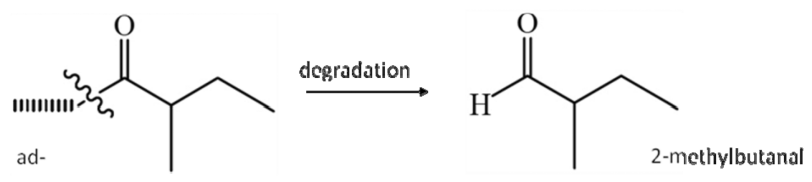

Fig. 5. Hypothetical pathway for the formation of aldehydes from isohumulones, assuming the deacylation of the side chain at $\mathrm{C}(2)$ of the molecule, leading to respectively 2-methylpropanal from isocohumulone, 3-methylbutanal from isohumulone, and 2-methylbutanal from isoadhumulone.

ids by proton-catalysed cyclisation during storage of beer, were very recently identified by simulation of the transspecific degradation in quantitative model experiments as

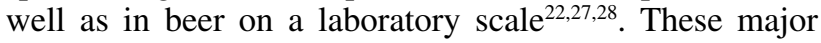
transformation products explain the storage-induced changes of the bitter taste of beer towards a lingering, more harsh bitterness. Regarding the formation of volatile compounds from isohumulones, it has been reported that the oxidative degradation of isohumulones based on radical reactions produces aldehydes participating in stale flavour formation ${ }^{18,19,20,33}$. According to Kaneda et al. ${ }^{33}$, free radicals, such as hydroxyl radicals and the superoxide radical anion, oxidise isohumulones directly into aldehydes and ketones. Besides, they proposed hydroxyl radicals to initiate a series of radical reactions which, in turn, also oxidise isohumulones into the undesirable staling aldehydes. According to Hashimoto and Eshima ${ }^{18}$, the portion of the isohumulone molecule that is degraded, is the carbonyl group or the unsaturated bond of the isohexenoyl side chain at $\mathrm{C}(4)$ of the molecule. Hashimoto and Eshima $^{18,19}$ showed the formation of carbonyl compounds with various side chain lengths, such as C3-C11 2-alkanones, C2-C10 alkanals, C4-C7 2-alkenals and C6-C7 2,4-alkadienals, in beer model systems. Additionally, acetone, 2-methylpropanal, 3-methyl-butan-2-one, methyl isobutyl ketone, 2-methyl-3-buten-2-ol' ${ }^{20}$, and several acids, namely 2-methylpropionate, 2-methylbutyrate and 3-methylbutyrate, were also identified as bitter acids degradation products ${ }^{54}$. In particular the formation of the staling aldehydes 2-methylpropanal, 2-methylbutanal and 3methylbutanal by oxidative cleavage of the various acyl and alkenyl side chains present in isohumulones during forced ageing of beer samples, has been the subject of further investigation within the present study. In Fig. 5, another hypothetical pathway for the formation of these aldehydes from isohumulones is proposed, assuming the deacylation of the side chain at $\mathrm{C}(2)$ of the molecule, leading to respectively 2-methylpropanal from isocohumulone, 3-methylbutanal from isohumulone, and 2-methylbutanal from isoadhumulone. Furthermore, photodegradation and radical-assisted oxidation, by which isohu- mulones undergo oxidative decomposition by electron loss in the presence of suitable electron acceptors and which does not necessarily require oxygen species, are also generally accepted to be responsible for the generation of pungent off-odour compounds ${ }^{21,25,26}$.

As the aldehydes 2-methylpropanal, 2-methylbutanal and 3-methylbutanal, putative degradation products of iso$\alpha$-acids, are also identified as Strecker degradation aldehydes, the pathway leading to these aldehydes upon beer ageing is not absolute. Nevertheless, considering the reactivity of trans-iso- $\alpha$-acids and the alleged stability of cisiso- $\alpha$-acids, one would expect a different increase in these specific aldehydes during storage if their formation is linked to the trans-specific conversion of iso- $\alpha$-acids. From this point of view, it is relevant to study the generation of these volatile off-flavours in beers with a significantly enhanced and reduced level of trans-iso- $\alpha$-acids relative to $c i s$-iso- $\alpha$-acids during forced ageing, the results of which are presented in this paper. Consequently, pure trans- respectively cis-isomers were required in large amounts for post-fermentation addition to finished beer. Separation of trans- from $c$ is-iso- $\alpha$-acids in a commercial isomerised hop extract was accomplished on a pilot scale by the formation of trans-iso- $\alpha$-acids $\beta$-cyclodextrin inclusion complexes according to our in-house procedure based on Khatib et al. ${ }^{34,35}$, permitting the quantitative dosage to beer in $\mathrm{mg} / \mathrm{L}$ amounts (see Materials and Methods).

\section{Evaluation of the stability of iso- $\alpha$-acids during beer ageing and the effect of $\mathrm{C} / \mathrm{T}$-ratio}

The iso- $\alpha$-acids profiles of all bittered beers derived from the two basic brews obtained with two different malts (Table I) were analysed by HPLC immediately after bottling (fresh samples) and after forced ageing in the dark at $30^{\circ} \mathrm{C}$ for $30,60,90,120$, and 150 days. The applied chromatographic methodology ${ }^{10}$ resulted in full separation of the six individual iso- $\alpha$-acids, allowing a detailed study of iso- $\alpha$-acids behaviour during beer storage. This is most interesting in view of the beers bittered with high amounts of trans- respectively $c i s$-iso- $\alpha$-acids, since it is, in our opinion, the first time that the behaviour of these two types of stereoisomers of the bitter acids has been studied in pilot beers at particularly high and low proportions of the trans-iso- $\alpha$-acids concentration relative to the $c i s$-iso- $\alpha$-acids concentration. Table II shows the levels of individual trans-iso- $\alpha$-acids and cis-iso- $\alpha$-acids in the fresh and aged beers, respectively. The ageing properties of iso- $\alpha$-acids are presented as the ratio of the sum of the concentration of trans-isocohumulone and transisohumulone to the sum of the concentration of cis-isocohumulone and cis-isohumulone (T/C-ratio), and vice versa (C/T-ratio) (Table II). The T/C-ratio has been previously proposed as a good marker for flavour deterioration of beer $^{2,10}$ and a relevant parameter in the overall evaluation of beer flavour stability ${ }^{38,43}$. However, the concentration ratio of cis/trans-isomers (C/T-ratio) is considered an additional useful tool in this study, as the differences in the iso- $\alpha$-acids profiles, according to the applied bittering, were better reflected by it. As shown by the calculated C/T-ratios (Table II), enrichment of cis-iso- $\alpha$-acids was pronounced in both fresh Cis-beers. Other than the typical C/T-ratios of 3.34 and 2.63 for the fresh Iso-beers, the 
Table II. Average values (standard deviation in parentheses; $\mathrm{n}=4$ ) of the concentrations of iso- $\alpha$-acids $(\mathrm{mg} / \mathrm{L})$ in fresh and forced aged $\left(30^{\circ} \mathrm{C}\right)$ pilot beer samples, derived from two basic 2-hL brews, prepared with malt A and B, respectively. Fresh: fresh beer sample; $30 \mathrm{~d} 30^{\circ} \mathrm{C}$, $60 \mathrm{~d} 30^{\circ} \mathrm{C}, 90 \mathrm{~d} 30^{\circ} \mathrm{C}$, $120 \mathrm{~d} 30^{\circ} \mathrm{C}, 150 \mathrm{~d} 30^{\circ} \mathrm{C}$ : beer sample aged for respectively $30,60,90,120$, and 150 days at $30^{\circ} \mathrm{C}$. Compound identification: t-ich: trans-isocohumulone; c-ich: cis-isocohumulone; t-inh: trans-isohumulone; c-inh: cis-isohumulone; t-iah: trans-isoadhumulone; c-iah: cis-isoadhumulone.

\begin{tabular}{|c|c|c|c|c|c|c|c|c|c|c|}
\hline Beer & Sample & t-ich & c-ich & t-inh & c-inh & t-iah & c-iah & Sum iso- $\alpha$-acids & T/C-ratio & C/T-ratio \\
\hline \multirow[t]{6}{*}{ Iso-A } & fresh & $1.7(0.1)$ & $5.7(0.1)$ & $2.8(0.1)$ & $9.2(0.2)$ & $0.6(0.0)$ & $2.0(0.1)$ & $21.9(0.4)$ & 0.30 & 3.34 \\
\hline & $30 \mathrm{~d} 30^{\circ} \mathrm{C}$ & $1.5(0.1)$ & $5.6(0.2)$ & $2.3(0.1)$ & $8.9(0.2)$ & $0.6(0.0)$ & $1.9(0.1)$ & $20.8(0.7)$ & 0.26 & 3.82 \\
\hline & $60 \mathrm{~d} 30^{\circ} \mathrm{C}$ & $1.4(0.0)$ & $5.6(0.1)$ & $2.1(0.1)$ & $8.7(0.1)$ & $0.5(0.0)$ & $1.9(0.0)$ & $20.2(0.3)$ & 0.24 & 4.09 \\
\hline & $90 \mathrm{~d} 30^{\circ} \mathrm{C}$ & $1.1(0.0)$ & $5.6(0.0)$ & $1.8(0.0)$ & $8.9(0.1)$ & $0.4(0.0)$ & $2.0(0.1)$ & $19.9(0.1)$ & 0.20 & 4.97 \\
\hline & $120 \mathrm{~d} 30^{\circ} \mathrm{C}$ & $1.0(0.0)$ & $5.6(0.1)$ & $1.6(0.0)$ & $8.7(0.0)$ & $0.4(0.0)$ & $2.0(0.1)$ & $19.3(0.2)$ & 0.19 & 5.39 \\
\hline & $150 \mathrm{~d} 30^{\circ} \mathrm{C}$ & $0.9(0.0)$ & $5.2(0.1)$ & $1.4(0.0)$ & $8.5(0.1)$ & $0.4(0.0)$ & $1.9(0.0)$ & $18.2(0.3)$ & 0.17 & 5.99 \\
\hline \multirow[t]{6}{*}{ Cis-A } & fresh & $0.3(0.0)$ & $8.3(0.4)$ & $0.3(0.0)$ & $12.0(0.7)$ & $0.1(0.0)$ & $3.5(0.2)$ & $24.5(1.3)$ & 0.03 & 33.78 \\
\hline & $30 \mathrm{~d} 30^{\circ} \mathrm{C}$ & $0.3(0.0)$ & $7.9(0.2)$ & $0.3(0.0)$ & $11.4(0.4)$ & $0.1(0.0)$ & $3.3(0.1)$ & $23.3(0.7)$ & 0.03 & 35.02 \\
\hline & $60 \mathrm{~d} 30^{\circ} \mathrm{C}$ & $0.3(0.0)$ & $7.7(0.2)$ & $0.2(0.0)$ & $11.1(0.2)$ & $0.1(0.0)$ & $3.3(0.1)$ & $22.8(0.5)$ & 0.03 & 37.02 \\
\hline & $90 \mathrm{~d} 30^{\circ} \mathrm{C}$ & $0.3(0.0)$ & $7.6(0.1)$ & $0.2(0.0)$ & $10.9(0.2)$ & $0.1(0.0)$ & $3.2(0.1)$ & $22.4(0.4)$ & 0.03 & 37.84 \\
\hline & $120 \mathrm{~d} 30^{\circ} \mathrm{C}$ & $0.2(0.0)$ & $7.6(0.2)$ & $0.2(0.0)$ & $10.9(0.3)$ & $0.1(0.0)$ & $3.2(0.1)$ & $22.2(0.6)$ & 0.02 & 41.86 \\
\hline & $150 \mathrm{~d} 30^{\circ} \mathrm{C}$ & $0.2(0.0)$ & $7.2(0.1)$ & $0.2(0.0)$ & $10.2(0.0)$ & $0.1(0.0)$ & $3.0(0.0)$ & $21.0(0.1)$ & 0.02 & 42.44 \\
\hline \multirow[t]{6}{*}{ Trans-A } & fresh & $8.0(0.1)$ & $1.0(0.0)$ & $12.5(0.2)$ & $1.6(0.0)$ & $2.7(0.0)$ & $0.3(0.0)$ & $26.1(0.4)$ & 7.90 & 0.13 \\
\hline & $30 \mathrm{~d} 30^{\circ} \mathrm{C}$ & $6.1(0.1)$ & $1.6(0.1)$ & $9.2(0.1)$ & $2.6(0.1)$ & $2.0(0.0)$ & $0.6(0.0)$ & $22.1(0.3)$ & 3.68 & 0.27 \\
\hline & $60 \mathrm{~d} 30^{\circ} \mathrm{C}$ & $5.8(0.2)$ & $1.1(0.1)$ & $8.7(0.3)$ & $1.8(0.1)$ & $1.9(0.1)$ & $0.4(0.1)$ & $19.6(0.3)$ & 5.12 & 0.20 \\
\hline & $90 \mathrm{~d} 30^{\circ} \mathrm{C}$ & $5.1(0.1)$ & $1.0(0.0)$ & $7.5(0.2)$ & $1.7(0.0)$ & $1.6(0.0)$ & $0.3(0.0)$ & $17.3(0.3)$ & 4.65 & 0.21 \\
\hline & $120 \mathrm{~d} 30^{\circ} \mathrm{C}$ & $4.2(0.1)$ & $1.2(0.0)$ & $6.0(0.1)$ & $2.0(0.0)$ & $1.3(0.0)$ & $0.4(0.0)$ & $15.1(0.1)$ & 3.14 & 0.32 \\
\hline & $150 \mathrm{~d} 30^{\circ} \mathrm{C}$ & $3.6(0.0)$ & $1.1(0.0)$ & $5.1(0.0)$ & $1.8(0.0)$ & $1.1(0.0)$ & $0.4(0.0)$ & $13.0(0.0)$ & 3.07 & 0.33 \\
\hline \multirow[t]{6}{*}{ Iso-B } & fresh & $1.8(0.1)$ & $4.8(0.1)$ & $2.4(0.1)$ & $6.1(0.1)$ & $0.6(0.0)$ & $1.9(0.0)$ & $17.5(0.2)$ & 0.38 & 2.63 \\
\hline & $30 \mathrm{~d} 30^{\circ} \mathrm{C}$ & $1.7(0.0)$ & $4.7(0.0)$ & $2.2(0.0)$ & $5.9(0.0)$ & $0.6(0.0)$ & $1.8(0.0)$ & $16.8(0.1)$ & 0.36 & 2.77 \\
\hline & $60 \mathrm{~d} 30^{\circ} \mathrm{C}$ & $1.6(0.0)$ & $4.5(0.0)$ & $2.1(0.0)$ & $5.8(0.0)$ & $0.6(0.0)$ & $1.8(0.0)$ & $16.4(0.0)$ & 0.36 & 2.77 \\
\hline & $90 \mathrm{~d} 30^{\circ} \mathrm{C}$ & $1.1(0.0)$ & $4.5(0.0)$ & $1.4(0.0)$ & $5.8(0.0)$ & $0.4(0.0)$ & $1.7(0.0)$ & $14.9(0.0)$ & 0.25 & 4.02 \\
\hline & $120 \mathrm{~d} 30^{\circ} \mathrm{C}$ & $1.1(0.0)$ & $4.4(0.0)$ & $1.3(0.0)$ & $5.6(0.0)$ & $0.4(0.0)$ & $1.7(0.0)$ & $14.4(0.0)$ & 0.23 & 4.32 \\
\hline & $150 \mathrm{~d} 30^{\circ} \mathrm{C}$ & $1.0(0.0)$ & $4.3(0.0)$ & $1.2(0.0)$ & $5.4(0.0)$ & $0.4(0.0)$ & $1.6(0.0)$ & $13.9(0.1)$ & 0.22 & 4.45 \\
\hline \multirow[t]{6}{*}{ Cis-B } & fresh & $0.3(0.0)$ & $6.9(0.0)$ & $0.3(0.0)$ & $10.0(0.0)$ & $0.2(0.0)$ & $3.0(0.0)$ & $20.7(0.1)$ & 0.04 & 26.78 \\
\hline & $30 \mathrm{~d} 30^{\circ} \mathrm{C}$ & $0.3(0.0)$ & $6.3(0.0)$ & $0.3(0.0)$ & $9.2(0.1)$ & $0.2(0.0)$ & $2.8(0.0)$ & $19.0(0.1)$ & 0.03 & 28.63 \\
\hline & $60 \mathrm{~d} 30^{\circ} \mathrm{C}$ & $0.3(0.0)$ & $6.4(0.1)$ & $0.3(0.0)$ & $9.4(0.1)$ & $0.1(0.0)$ & $2.9(0.1)$ & $19.4(0.3)$ & 0.03 & 30.38 \\
\hline & $90 \mathrm{~d} 30^{\circ} \mathrm{C}$ & $0.2(0.0)$ & $6.2(0.0)$ & $0.3(0.0)$ & $9.0(0.0)$ & $0.1(0.0)$ & $2.8(0.0)$ & $18.6(0.1)$ & 0.03 & 31.60 \\
\hline & $120 \mathrm{~d} 30^{\circ} \mathrm{C}$ & $0.2(0.0)$ & $6.2(0.1)$ & $0.2(0.0)$ & $8.9(0.2)$ & $0.1(0.0)$ & $2.8(0.1)$ & $18.4(0.3)$ & 0.03 & 34.14 \\
\hline & $150 \mathrm{~d} 30^{\circ} \mathrm{C}$ & $0.2(0.0)$ & $6.3(0.0)$ & $0.2(0.0)$ & $8.9(0.0)$ & $0.1(0.0)$ & $2.8(0.0)$ & $18.5(0.0)$ & 0.03 & 36.00 \\
\hline \multirow[t]{6}{*}{ Trans-B } & fresh & $7.6(0.3)$ & $1.2(0.1)$ & $12.0(0.4)$ & $1.9(0.1)$ & $2.6(0.1)$ & $0.5(0.0)$ & $25.8(0.9)$ & 6.32 & 0.16 \\
\hline & $30 \mathrm{~d} 30^{\circ} \mathrm{C}$ & $6.5(0.2)$ & $1.2(0.1)$ & $10.1(0.3)$ & $1.9(0.1)$ & $2.2(0.1)$ & $0.5(0.0)$ & $22.5(0.7)$ & 5.31 & 0.19 \\
\hline & $60 \mathrm{~d} 30^{\circ} \mathrm{C}$ & $6.1(0.1)$ & $1.6(0.1)$ & $9.3(0.2)$ & $2.6(0.1)$ & $2.0(0.0)$ & $0.7(0.0)$ & $22.4(0.6)$ & 3.64 & 0.27 \\
\hline & $90 \mathrm{~d} 30^{\circ} \mathrm{C}$ & $5.3(0.2)$ & $1.5(0.1)$ & $8.0(0.2)$ & $2.4(0.2)$ & $1.8(0.0)$ & $0.7(0.1)$ & $19.7(0.1)$ & 3.37 & 0.30 \\
\hline & $120 \mathrm{~d} 30^{\circ} \mathrm{C}$ & $4.6(0.0)$ & $1.5(0.1)$ & $6.9(0.1)$ & $2.3(0.1)$ & $1.5(0.0)$ & $0.6(0.0)$ & $17.4(0.0)$ & 3.07 & 0.33 \\
\hline & $150 \mathrm{~d} 30^{\circ} \mathrm{C}$ & $4.5(0.0)$ & $1.4(0.0)$ & $6.6(0.0)$ & $2.2(0.0)$ & $1.4(0.0)$ & $0.6(0.0)$ & $16.7(0.1)$ & 3.04 & 0.33 \\
\hline
\end{tabular}

initial content of cis-iso- $\alpha$-acids in the Cis-A and Cis-B beers resulted in C/T-ratios of 33.78 and 26.78, respecttively. The initial total bitterness of the Cis-A and Cis-B beers was respectively 24.5 and $20.7 \mathrm{mg}$ of iso- $\alpha$-acids per L, of which $23.8 \mathrm{mg}$ or $97 \%$, respectively $19.9 \mathrm{mg}$ or $96 \%$, were cis-iso- $\alpha$-acids. On the other hand, the different proportion of the trans-iso- $\alpha$-acids concentration to the $c i s$-iso- $\alpha$-acids concentration in the fresh Trans-A and Trans-B beers resulted in the extreme low C/T-ratios of 0.13 and 0.16 . The initial total bitterness of the Transbeers was approximately $26 \mathrm{mg}$ of iso- $\alpha$-acids per L, of which on average $87 \%$ were trans-iso- $\alpha$-acids.

In the Iso-beers, in which bittering with commercial isomerised hop extract was performed at the post-fermentation stage, a gradual decrease in analytical bitterness was observed as a function of the ageing time. Total bitterness in the fresh Iso-A beer was $21.9 \mathrm{mg}$ of iso- $\alpha$-acids per $\mathrm{L}(100 \%)$. After 30 days at $30^{\circ} \mathrm{C}$, total bitterness was reduced by approx. 5\% (Table II). At the end of the experimental ageing period $\left(150\right.$ days at $\left.30^{\circ} \mathrm{C}\right), 18.2 \mathrm{mg}$ of iso- $\alpha$-acids per $\mathrm{L}$ were measured, representing a relative decrease in total bitterness of $17 \%$. The changes in the relative concentrations of the individual iso- $\alpha$-acids in the Iso-A beer upon forced ageing at $30^{\circ} \mathrm{C}$ are represented in Fig. 6. Decay of the trans-isomers upon ageing is obvious from the data depicted in this Figure, whereas the levels of their cis counterparts showed only a minor decrease. This differential behaviour of the two types of stereoisomers is in full agreement with results obtained during our previous research, demonstrating that especially trans-iso$\alpha$-acids are sensitive towards oxidative degradation upon beer ageing $9,10,11,32,38,43$. For the Iso-B beer exactly the same conclusion was reached, with a relative decrease in total bitterness of $20 \%$ after 150 days at $30^{\circ} \mathrm{C}$ (Table II).

Compatibility with the hypothesis if relatively less trans-isomers also leads to better bitterness stability in the final beer and prolonged overall flavour stability, was examined with the Cis-beers. The changes in the relative concentrations of the individual iso- $\alpha$-acids upon forced ageing at $30^{\circ} \mathrm{C}$ are depicted in Fig. 7 for Cis-A. As expected from the higher stability of the cis-isomers in beers bittered with commercial isomerised hop extract, an overall better bitterness stability was observed in the presence of only minor amounts of trans-isohumulones in the Cisbeers. The cis-isohumulones remained largely unaltered, so that at the end of the experimental ageing period, the residual relative total concentration of iso- $\alpha$-acids in Cis$\mathrm{A}$ and Cis-B was $85.5 \%$ and $89.2 \%$ respectively. Notwithstanding the low amounts of trans-iso- $\alpha$-acids present in the fresh Cis-beers, degradation of these components was clearly observed. The relatively slower decrease upon ageing compared with the reference Iso-beers was mainly 


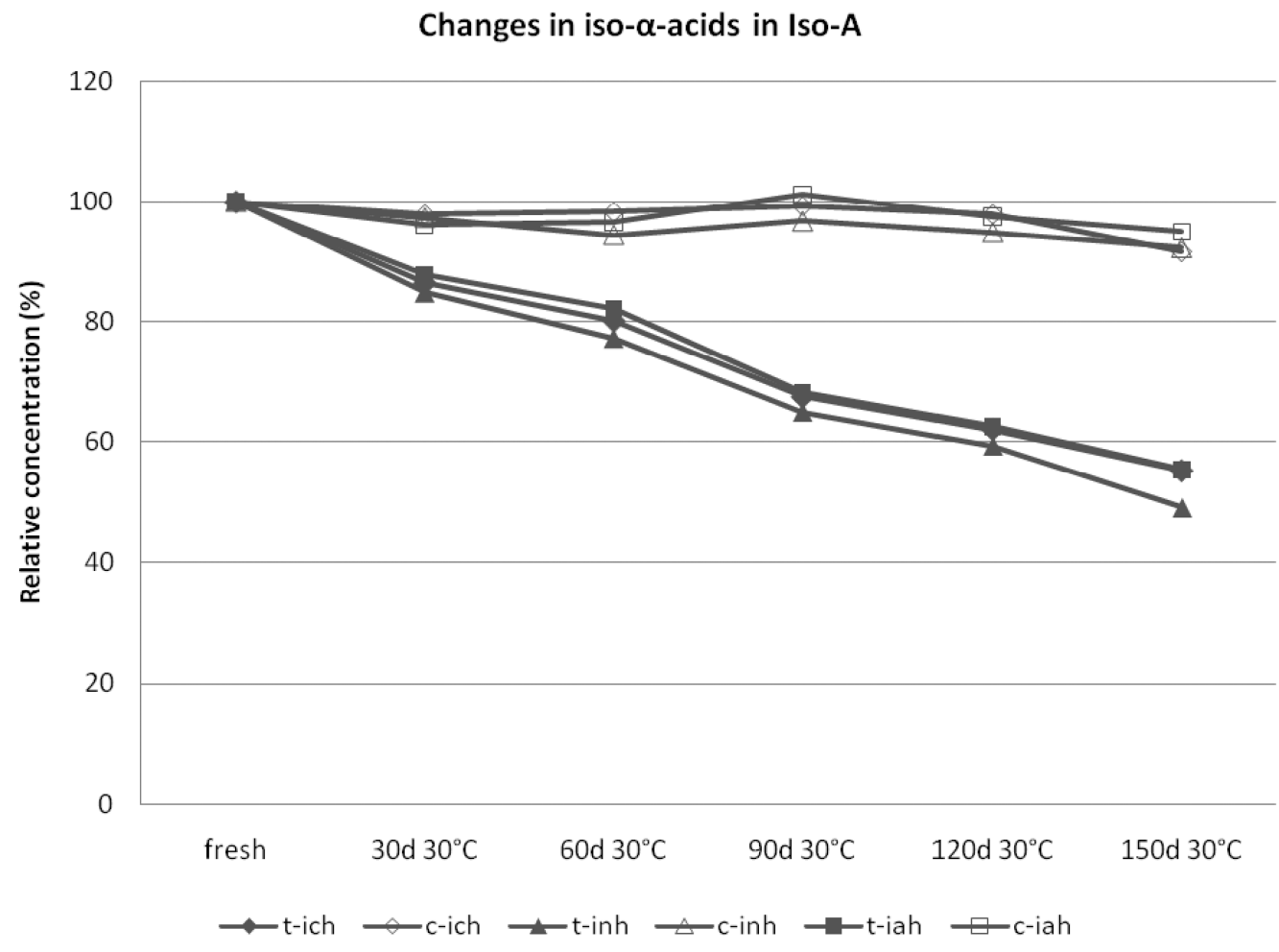

Fig. 6. Relative concentrations of trans- and cis-iso- $\alpha$-acids in the Iso-A beer as a function of forced ageing at $30^{\circ} \mathrm{C}$. Compound identification: t-ich: trans-isocohumulone; c-ich: cis-isocohumulone; t-inh: trans-isohumulone; c-inh: cis-isohumulone; t-iah: trans-isoadhumulone; c-iah: cis-isoadhumulone.

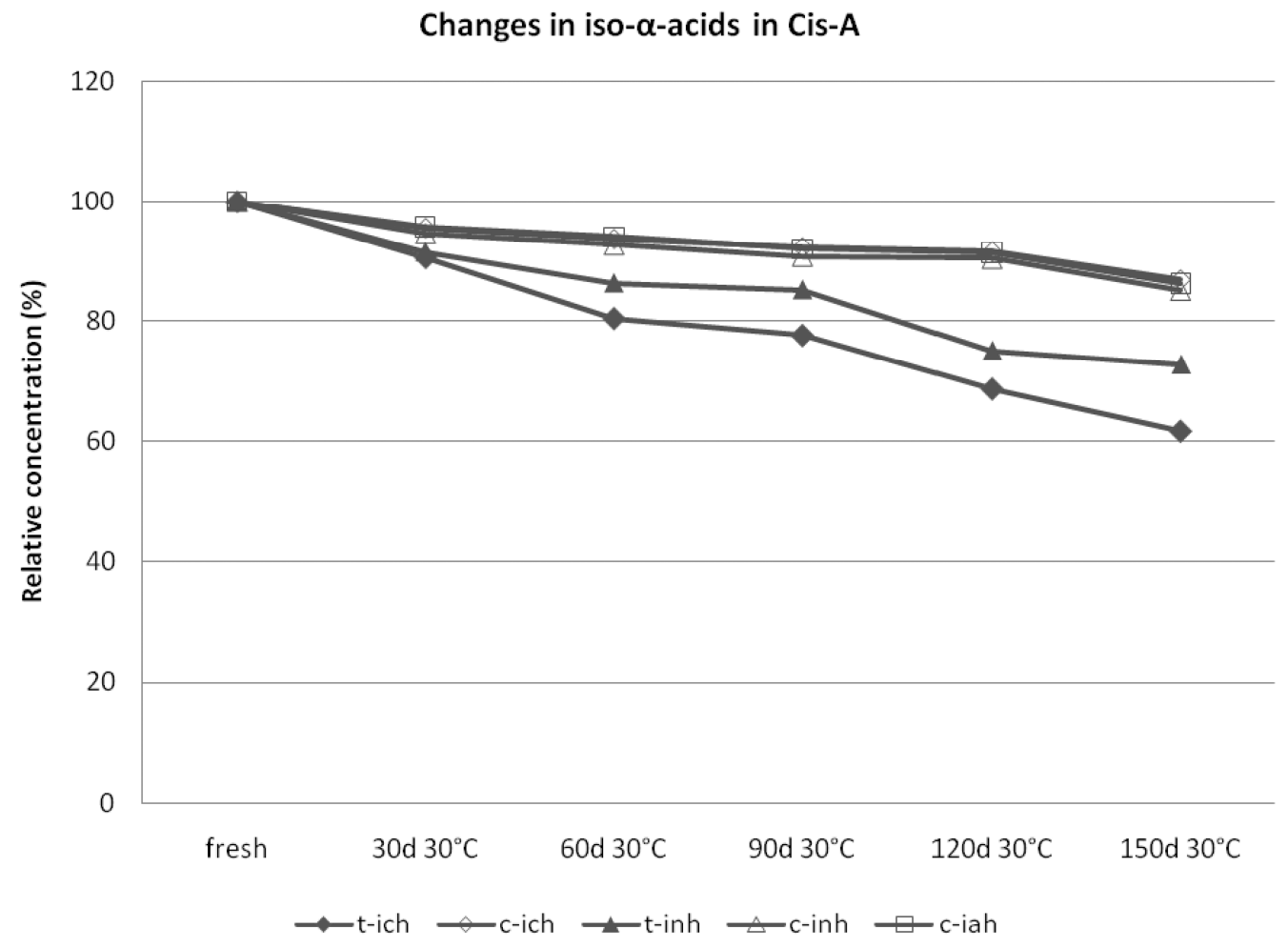

Fig. 7. Relative concentrations of trans- and cis-iso- $\alpha$-acids in the Cis-A beer as a function of forced ageing at $30^{\circ} \mathrm{C}$. Compound identification: $\mathrm{t}$-ich: trans-isocohumulone; $\mathrm{c}$-ich: cis-isocohumulone; t-inh: trans-isohumulone; c-inh: cis-isohumulone; c-iah: cis-isoadhumulone. 


\section{Changes in iso- $\alpha$-acids in Trans-A}

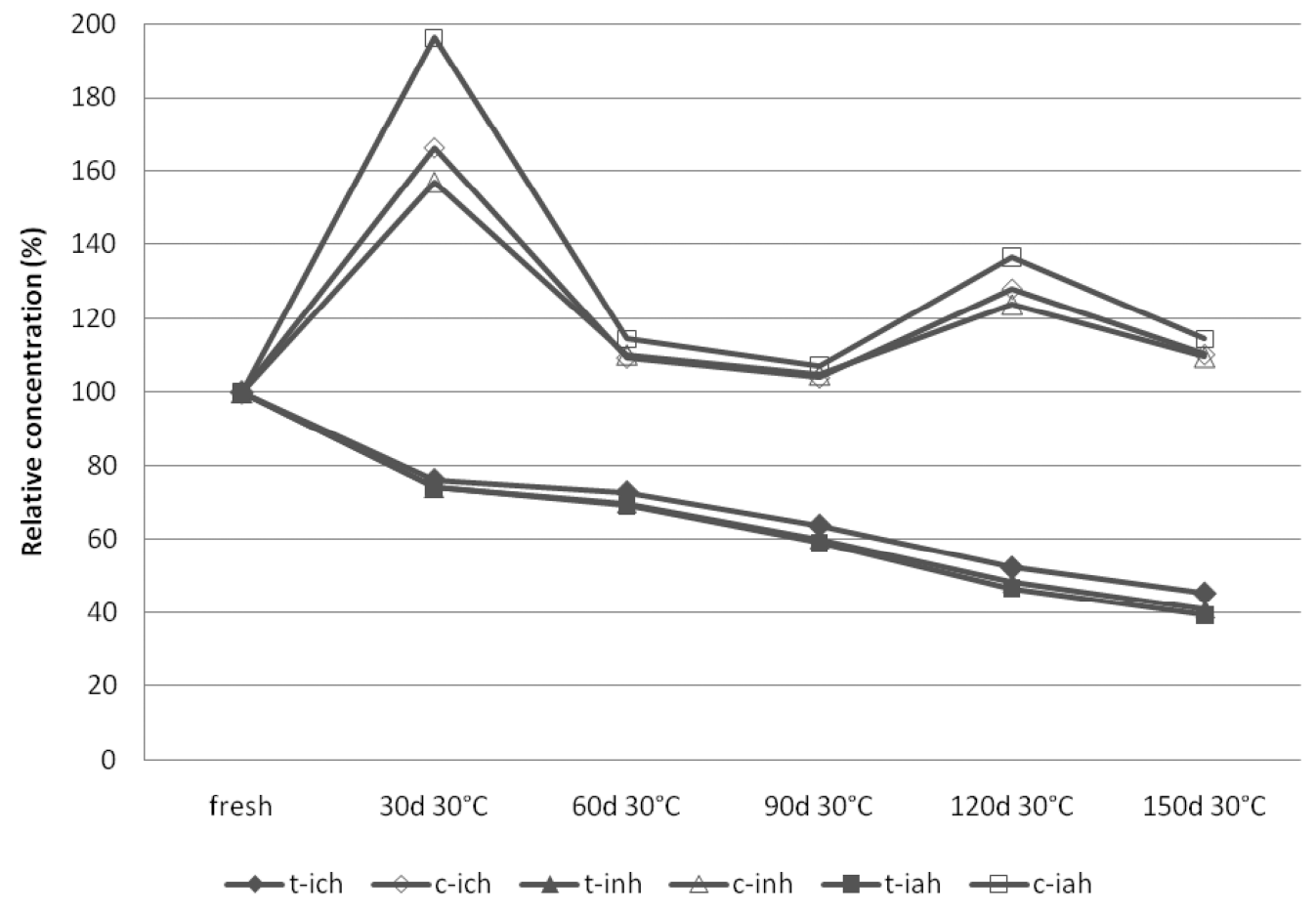

Fig. 8. Relative concentrations of trans- and $c i s$-iso- $\alpha$-acids in the Trans-A beer as a function of forced ageing at $30^{\circ} \mathrm{C}$. Compound identification: t-ich: trans-isocohumulone; c-ich: cis-isocohumulone; t-inh: trans-isohumulone; c-inh: cis-isohumulone; t-iah: trans-isoadhumulone; c-iah: cis-isoadhumulone.

caused by the very low amounts of trans-iso- $\alpha$-acids present in the Cis-beers.

The relatively fast conversion of trans-iso- $\alpha$-acids versus $c i s$-iso- $\alpha$-acids is also apparent in Fig. 8, representing the changes in the relative concentrations of the individual iso- $\alpha$-acids in the Trans-A beer upon forced ageing at $30^{\circ} \mathrm{C}$. As is noticeable from this Figure, trans-iso- $\alpha$-acids deteriorated at an even faster rate throughout the ageing period compared with the beers in which the conventional, reduced amount of trans-iso- $\alpha$-acids was present (Iso A and Iso B). After 150 days at $30^{\circ} \mathrm{C}$, approximately $40 \%$ of the initial trans-iso- $\alpha$-acids remained in the TransA beer, against around $50-55 \%$ in the Iso-beers (Table II). Obviously, due to the high proportion of trans-iso- $\alpha$-acids relative to cis-iso- $\alpha$-acids in the Trans-A and Trans-B beers, the decay of trans-iso- $\alpha$-acids upon ageing resulted in a decrease to $50 \%$ respectively $65 \%$ of the initial total bitterness after 150 days at $30^{\circ} \mathrm{C}$, whereas in the Iso-beers a total bitterness of around $80 \%$ remained after this ageing period. These results confirm the instability of transiso- $\alpha$-acids as previously explained in this paper by the $c i s$ configuration of the side chains at $\mathrm{C}(4)$ and $\mathrm{C}(5)$ in these molecules (Fig. 2), establishing a region of high electron density, allowing ready initiation of radical oxidation reactions ${ }^{10}$. On the contrary, a remarkable increase in the relative concentration of $c i$ s-iso- $\alpha$-acids up to $150-200 \%$ was observed after 30 respectively 60 days at $30^{\circ} \mathrm{C}$ in the Trans-A and Trans-B beers. Although conversion of cisiso- $\alpha$-acids was visible, the remaining relative concentration of $c i$-iso- $\alpha$-acids in the Trans-beers was still 110 $120 \%$ after 150 days at $30^{\circ} \mathrm{C}$. To our knowledge, this phe- nomenon has been demonstrated for the first time in a beer matrix and the only apparent reason for it are the very low concentrations of cis-isomers and the very high proportion of their trans-counterparts in the Trans-beer matrix. A possible explanation of the considerable increase of cis-isohumulones detected in the Trans-beers, may lie in the fact that $c i s$-iso- $\alpha$-acids are thermodynamically more stable than their trans-counterparts ${ }^{31}$, the reason for which the cis/trans-iso- $\alpha$-acids ratio is typically 7:3 in commercial isomerised hop extracts ${ }^{23,49}$. The observations in the Trans-beers may be ascribed to partial conversion, i.e., reverse isomerisation, of trans-iso- $\alpha$-acids via $\alpha$-acids into $c i s$-iso- $\alpha$-acids. Based on activation energies of individual trans-iso- $\alpha$-acids and cis-iso- $\alpha$-acids obtained in a kinetic study on the isomerisation of hop $\alpha$ acids, Jaskula et al. ${ }^{31}$ proposed a free energy diagram for the conversion of these $\alpha$-acids into trans- and cis-iso- $\alpha$ acids. According to this diagram (Fig. 9), trans-cis interconversion, i.e., conversion of trans-iso- $\alpha$-acids via $\alpha$-acids into cis-iso- $\alpha$-acids, is more likely to occur than cistrans interconversion. Starting from pure trans-iso- $\alpha$-acids, the free energy of activation required to attain the transition state in the formation of $\alpha$-acids, is lower than starting from pure $c i s$-iso- $\alpha$-acids. Despite the higher activation energies required for $c i s$-isomer formation from $\alpha$ acids, this configuration is energetically favoured, since the finished product, a cis-iso- $\alpha$-acid, has indeed a lower free energy, i.e., a higher stability from the thermodynamic point of view, compared to its trans-counterpart. In cis-iso- $\alpha$-acids, the bulky side chains at $\mathrm{C}(4)$ and $\mathrm{C}(5)$ are actually in the trans-configuration, indeed leading to more 
low energy conformations with a resultant increase in entropy, compared to that of trans-iso- $\alpha$-acids ${ }^{24}$. Trans-cis interconversion was previously reported by Verzele and De Keukeleire ${ }^{49}$ and demonstrated both in heated buffer systems and boiling wort, starting from pure trans-iso- $\alpha-$ acids $^{31}$. At first sight, the proposed trans-cis interconversion is also compatible with our results observed in the Trans-beers, revealing an increase in the cis-iso- $\alpha$-acids concentrations after prolonged storage time at moderate temperature $\left(30-60\right.$ days at $30^{\circ} \mathrm{C}$ ) while the trans-isohumulones decreased. With respect to cis-trans interconversion, it is expected that starting from pure cis-iso- $\alpha-$

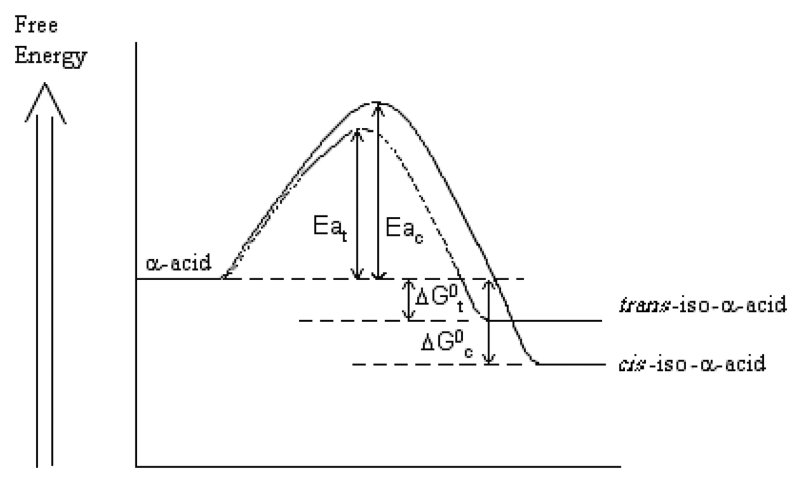

Fig. 9. Free energy diagram for the formation of trans- and cisiso- $\alpha$-acids from $\alpha$-acids as proposed by Jaskula et al. ${ }^{31}\left(\Delta \mathrm{G}^{\circ}\right.$, overall free energy change related to the formation of trans-iso$\alpha$-acids; $\Delta \mathrm{G}^{\circ}{ }_{\mathrm{c}}$, overall free energy change related to the formation of $c$ is-iso- $\alpha$-acids; $\mathrm{Ea}_{\mathrm{t}}$, free energy of activation related to the formation of trans-iso- $\alpha$-acids; $\mathrm{Ea}_{\mathrm{c}}$, free energy of activation related to the formation of $c i s$-iso- $\alpha$-acids). acids, as was aimed at in the Cis-beers, will give rise to far less trans-counterparts formation upon prolonged forced ageing, as trans-iso- $\alpha$-acid formation from $\alpha$-acids is energetically not favoured ${ }^{31}$, and moreover, the degradation of the trans-iso- $\alpha$-acids during ageing is probably the key pathway.

\section{Evaluation of the likely formation of volatile aldehydes from isohumulones}

To estimate the impact of deterioration of iso- $\alpha$-acids on the flavour stability of beer, formation of related carbonyl compounds was studied. Initially, quantitative headspace SPME GC-MS profiling of 2-methylpropanal, 2methylbutanal and 3-methylbutanal was performed on the fresh and forced aged (30, 60, 90, 120 and 150 days at $30^{\circ} \mathrm{C}$ in the dark) beer samples Iso-A, Cis-A, Trans-A, and Blank-A, all derived from the first basic brew obtained with malt A (Table I). The observations regarding the formation of these aldehydes upon ageing as a function of the different bittering applied, are summarised in Table III. The unhopped beer Blank-A, derived from the same basic brew, served as a reference. All reported results are the mean values of six measurements from two different bottles. Both the unhopped and bittered fresh Abeers contained similar levels of 2-methylpropanal (4.4$6.5 \mu \mathrm{g} / \mathrm{L}), 2$-methylbutanal $(1-2.5 \mu \mathrm{g} / \mathrm{L})$ and 3-methylbutanal $(5.7-6.6 \mu \mathrm{g} / \mathrm{L})$, respectively. These beers were indeed derived from one basic brew and divided for bittering not earlier than at the transfer fermentation-lagering. In Fig. 10, the increase in concentration of 2-methylpropanal upon forced ageing is represented. During storage, a considerable increase in the concentration of this aldehyde was noticed in all A-beers, which was irrespective of the mode of bittering. No relationship between the formation of 2-methylpropanal and the presence or absence of

Table III. Average values (standard deviation in parentheses; $\mathrm{n}=6$ ) of the concentrations of aldehydes $(\mu \mathrm{g} / \mathrm{L})$ in fresh and forced aged $\left(30^{\circ} \mathrm{C}\right)$ pilot beer samples, derived from the same basic 2-hL brew, prepared with malt A.

\begin{tabular}{|c|c|c|c|c|c|c|c|c|c|c|c|}
\hline Beer & Sample & $\begin{array}{l}\text { 2-Methyl- } \\
\text { propanal }\end{array}$ & $\begin{array}{l}\text { 2-Methyl- } \\
\text { butanal }\end{array}$ & $\begin{array}{l}\text { 3-Methyl- } \\
\text { butanal }\end{array}$ & $\begin{array}{l}\text { Methi- } \\
\text { onal }\end{array}$ & $\begin{array}{l}\text { Benzal- } \\
\text { dehyde }\end{array}$ & $\begin{array}{l}\text { Phenylac- } \\
\text { etaldehyde }\end{array}$ & Furfural & Hexanal & $t$-2-Nonenal & $\begin{array}{l}\text { Sum aldehyde } \\
\text { markers }\end{array}$ \\
\hline \multirow[t]{6}{*}{ Blank-A } & fresh & $6.1(0.5)$ & $2.5(0.1)$ & $5.7(0.2)$ & $4.0(0.1)$ & $1.2(0.0)$ & $4.6(0.2)$ & $5.8(0.1)$ & $1.0(0.1)$ & $0.03(0.00)$ & $30.9(1.2)$ \\
\hline & $30 \mathrm{~d} 30^{\circ} \mathrm{C}$ & $38.1(3.1)$ & $3.0(0.1)$ & $8.7(0.7)$ & $6.3(0.7)$ & $2.7(0.1)$ & $7.8(0.4)$ & $87.2(3.9)$ & $1.9(0.0)$ & $0.05(0.00)$ & $155.7(9.0)$ \\
\hline & $60 \mathrm{~d} 30^{\circ} \mathrm{C}$ & $54.1(0.6)$ & $3.4(0.1)$ & $10.8(0.3)$ & $8.1(0.8)$ & $3.2(0.1)$ & $10.1(0.8)$ & $160.3(7.8)$ & $2.2(0.2)$ & $0.07(0.00)$ & $252.2(10.7)$ \\
\hline & $90 \mathrm{~d} 30^{\circ} \mathrm{C}$ & $61.1(1.4)$ & $4.3(0.1)$ & $11.2(0.5)$ & $9.0(0.5)$ & $3.7(0.1)$ & $10.5(0.5)$ & 220.7 (7.6) & $2.5(0.1)$ & $0.08(0.00)$ & $323.1(10.7)$ \\
\hline & $120 \mathrm{~d} 30^{\circ} \mathrm{C}$ & $62.3(2.0)$ & $4.8(0.0)$ & $11.7(0.2)$ & $8.7(0.7)$ & $3.6(0.0)$ & $10.5(0.8)$ & $242.9(5.8)$ & $2.6(0.1)$ & $0.09(0.00)$ & $347.2(9.6)$ \\
\hline & $150 \mathrm{~d} 30^{\circ} \mathrm{C}$ & $66.8(1.6)$ & $5.7(0.1)$ & $12.0(0.3)$ & $8.9(0.5)$ & $3.7(0.1)$ & $10.7(0.5)$ & $275.9(8.7)$ & $2.7(0.1)$ & $0.10(0.00)$ & 386.5 (11.9) \\
\hline \multirow[t]{6}{*}{ Iso-A } & fresh & $4.8(0.1)$ & $1.0(0.0)$ & $6.6(0.0)$ & $1.5(0.0)$ & $2.6(0.0)$ & $3.1(0.2)$ & $6.5(0.3)$ & $0.5(0.0)$ & $0.02(0.00)$ & $26.6(0.7)$ \\
\hline & $30 \mathrm{~d} 30^{\circ} \mathrm{C}$ & $30.7(0.9)$ & $1.9(0.1)$ & $8.9(0.2)$ & $2.8(0.1)$ & $2.9(0.1)$ & $5.7(0.1)$ & $59.0(0.6)$ & $0.9(0.0)$ & $0.04(0.00)$ & $112.8(2.1)$ \\
\hline & $60 \mathrm{~d} 30^{\circ} \mathrm{C}$ & $41.8(1.0)$ & $2.6(0.2)$ & $10.0(0.4)$ & $4.1(0.0)$ & $3.3(0.1)$ & $6.7(0.5)$ & $104.1(0.5)$ & $1.1(0.0)$ & $0.04(0.00)$ & $173.8(2.7)$ \\
\hline & $90 \mathrm{~d} 30^{\circ} \mathrm{C}$ & $54.5(1.8)$ & $3.6(0.1)$ & $10.9(0.4)$ & $4.9(0.0)$ & $3.7(0.2)$ & $8.7(0.2)$ & $170.4(2.2)$ & $1.4(0.1)$ & $0.05(0.00)$ & $258.0(5.0)$ \\
\hline & $120 \mathrm{~d} 30^{\circ} \mathrm{C}$ & $61.7(0.2)$ & $4.0(0.0)$ & $11.1(0.1)$ & $4.9(0.2)$ & $3.7(0.1)$ & $8.2(0.3)$ & $223.5(6.2)$ & $1.5(0.0)$ & $0.05(0.00)$ & $318.6(7.1)$ \\
\hline & $150 \mathrm{~d} 30^{\circ} \mathrm{C}$ & $61.9(0.2)$ & $4.5(0.0)$ & $11.4(0.0)$ & $5.4(0.2)$ & $3.9(0.1)$ & $8.6(0.1)$ & $257.5(5.2)$ & $1.5(0.1)$ & $0.05(0.00)$ & 354.7 (5.9) \\
\hline \multirow[t]{6}{*}{ Cis- $\mathrm{A}$} & fresh & $6.5(0.2)$ & $1.3(0.0)$ & $6.0(0.2)$ & $4.5(0.3)$ & $2.0(0.1)$ & $4.8(0.3)$ & $4.7(0.2)$ & $1.0(0.1)$ & $0.02(0.00)$ & $30.9(1.4)$ \\
\hline & $30 \mathrm{~d} 30^{\circ} \mathrm{C}$ & $26.3(0.9)$ & $2.2(0.1)$ & $8.7(0.1)$ & $5.8(0.2)$ & $2.5(0.0)$ & $7.0(0.4)$ & $55.3(0.8)$ & $1.6(0.0)$ & $0.04(0.00)$ & $109.5(2.5)$ \\
\hline & $60 \mathrm{~d} 30^{\circ} \mathrm{C}$ & $39.8(1.8)$ & $3.1(0.0)$ & $10.0(0.2)$ & $7.2(0.2)$ & $3.0(0.0)$ & $9.1(0.4)$ & $129.1(3.1)$ & $2.0(0.1)$ & $0.05(0.00)$ & $203.4(5.9)$ \\
\hline & $90 \mathrm{~d} 30^{\circ} \mathrm{C}$ & $43.2(2.3)$ & $3.6(0.1)$ & $10.8(0.2)$ & $8.1(0.3)$ & $3.4(0.1)$ & $10.2(0.5)$ & $145.2(5.8)$ & $2.4(0.1)$ & $0.05(0.00)$ & $226.9(9.3)$ \\
\hline & $120 \mathrm{~d} 30^{\circ} \mathrm{C}$ & $46.3(1.1)$ & $4.2(0.1)$ & $11.5(0.3)$ & $8.7(0.4)$ & $3.8(0.0)$ & $10.7(0.7)$ & $190.0(6.4)$ & $2.7(0.1)$ & $0.09(0.00)$ & $278.0(9.2)$ \\
\hline & $150 \mathrm{~d} 30^{\circ} \mathrm{C}$ & $47.9(1.7)$ & $5.0(0.1)$ & $11.2(0.3)$ & $8.6(0.4)$ & $3.5(0.1)$ & $12.7(0.6)$ & $283.1(14.8)$ & $2.5(0.1)$ & $0.09(0.00)$ & $374.4(18.2)$ \\
\hline \multirow[t]{6}{*}{ Trans-A } & fresh & $4.4(0.1)$ & $1.3(0.0)$ & $6.2(0.1)$ & $2.8(0.1)$ & $1.3(0.0)$ & $4.6(0.2)$ & $4.6(0.2)$ & $1.1(0.0)$ & $0.03(0.00)$ & $26.3(0.8)$ \\
\hline & $30 \mathrm{~d} 30^{\circ} \mathrm{C}$ & $37.3(0.7)$ & $2.3(0.1)$ & $9.3(0.4)$ & $4.4(0.2)$ & $1.8(0.1)$ & $7.8(0.5)$ & $82.2(2.7)$ & $1.7(0.1)$ & $0.05(0.00)$ & $146.8(4.8)$ \\
\hline & $60 \mathrm{~d} 30^{\circ} \mathrm{C}$ & $53.3(1.8)$ & $2.9(0.1)$ & $10.8(0.3)$ & $5.8(0.4)$ & $2.2(0.1)$ & $9.9(0.7)$ & $130.7(4.3)$ & $2.1(0.1)$ & $0.06(0.00)$ & $217.9(7.8)$ \\
\hline & $90 \mathrm{~d} 30^{\circ} \mathrm{C}$ & $58.6(2.1)$ & $3.7(0.0)$ & $11.3(0.1)$ & $6.3(0.5)$ & $2.6(0.0)$ & $10.5(0.8)$ & $154.4(3.6)$ & $2.3(0.1)$ & $0.07(0.00)$ & $249.8(7.2)$ \\
\hline & $120 \mathrm{~d} 30^{\circ} \mathrm{C}$ & $64.6(2.2)$ & $4.3(0.0)$ & $12.0(0.0)$ & $6.6(0.2)$ & $2.7(0.1)$ & $10.4(0.6)$ & $205.4(9.3)$ & $2.5(0.1)$ & $0.09(0.00)$ & $308.5(12.5)$ \\
\hline & $150 \mathrm{~d} 30^{\circ} \mathrm{C}$ & $65.8(1.2)$ & $4.8(0.2)$ & $12.4(0.4)$ & $7.7(0.5)$ & $3.3(0.1)$ & $10.7(0.7)$ & $284.5(11.9)$ & $3.5(0.1)$ & $0.10(0.00)$ & $392.9(15.1)$ \\
\hline
\end{tabular}

${ }^{\text {a }}$ Fresh: fresh beer sample; $30 \mathrm{~d} 30^{\circ} \mathrm{C}, 60 \mathrm{~d} 30^{\circ} \mathrm{C}, 90 \mathrm{~d} 30^{\circ} \mathrm{C}, 120 \mathrm{~d} 30^{\circ} \mathrm{C}, 150 \mathrm{~d} 30^{\circ} \mathrm{C}$ : beer sample aged for respectively $30,60,90,120$, and 150 days at $30^{\circ} \mathrm{C}$. 
more or less amounts of the easily degradable trans-iso- $\alpha$ acids in the beers could be proved. In particular, at the end of the experimental ageing period $\left(150\right.$ days at $\left.30^{\circ} \mathrm{C}\right)$, $66.8 \mu \mathrm{g}$ of 2-methylpropanal per $\mathrm{L}$ was measured in the unhopped beer Blank-A, which was at least as much as in the bittered beers Iso-A, Cis-A, and Trans-A. Also an increase in the content of 2-methylbutanal, respectively 3methylbutanal upon ageing is obvious from the data de- picted in the Fig. 11 and 12, although the levels of these aldehydes show only a minor increase in comparison with 2-methylpropanal. Yet, once more the increase of these branched aldehydes, also related to the decomposition of iso- $\alpha$-acids in the literature ${ }^{18,19,33}$, cannot be associated to the bittering applied in the experimental beers in this study, as the results of both the unhopped and the bittered beers were similar. These results are not in agreement

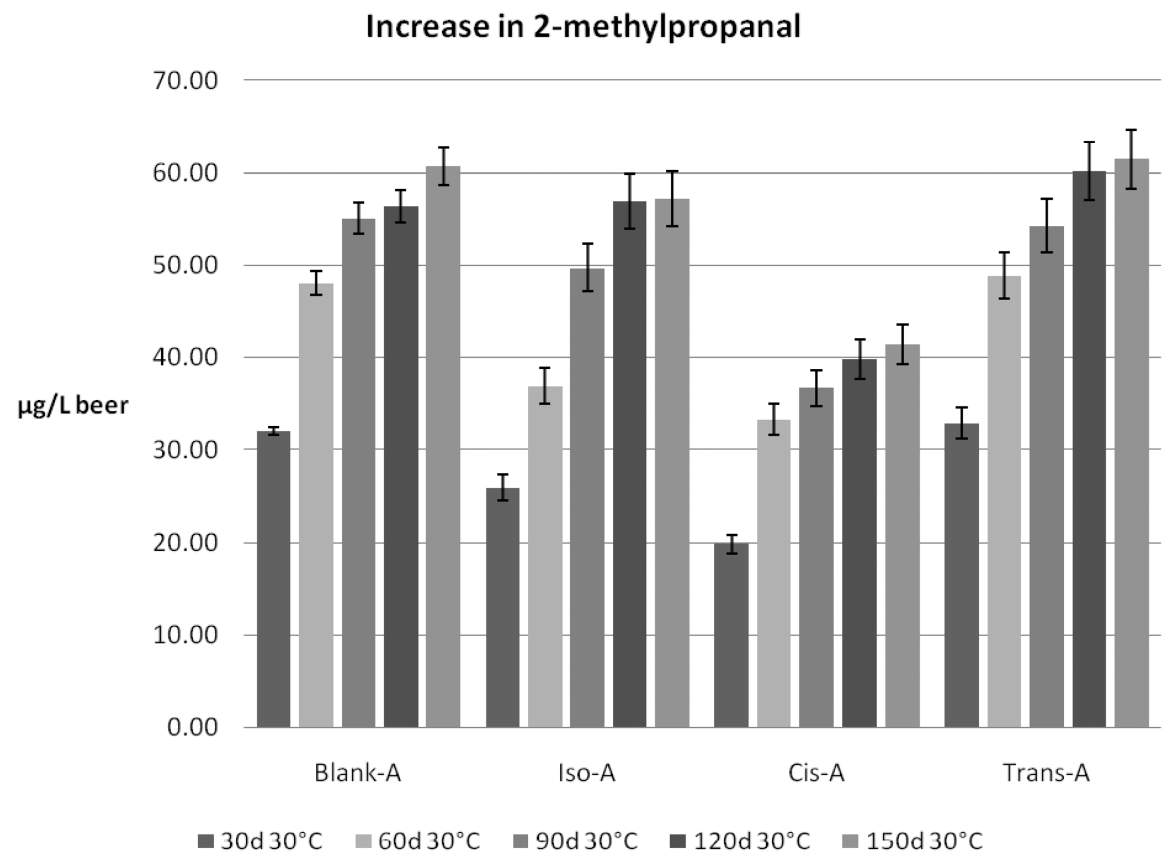

Fig. 10. Comparison of the increase in 2-methylpropanal during forced ageing $\left(30^{\circ} \mathrm{C}\right)$ as a function of the bittering regime of the pilot beers derived from brew A. Error bars represent the $95 \%$ confidence interval determined by Student's $t$-test; $\mathrm{n}=6$.

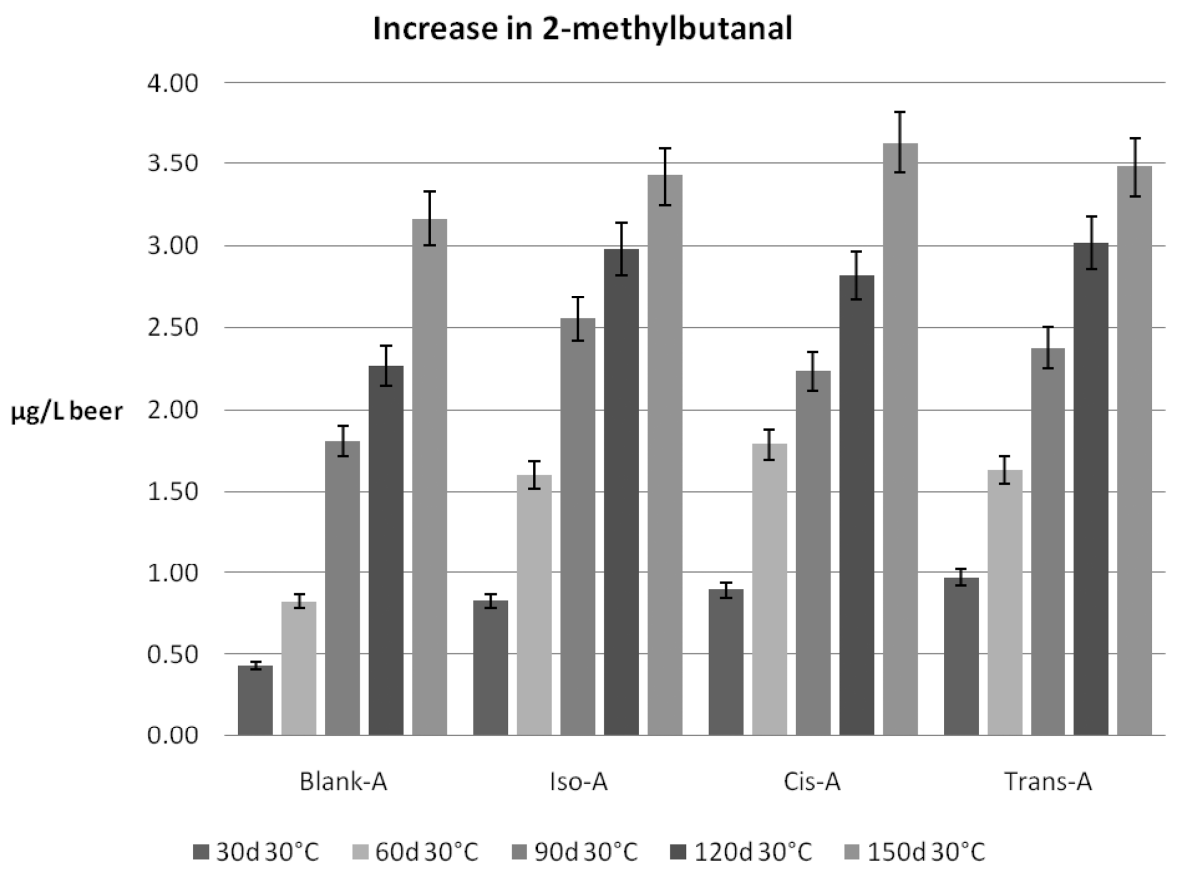

Fig. 11. Comparison of the increase in 2-methylbutanal during forced ageing $\left(30^{\circ} \mathrm{C}\right)$ as a function of the bittering regime of the pilot beers derived from brew A. Error bars represent the $95 \%$ confidence interval determined by Student's $t$-test; $\mathrm{n}=6$. 


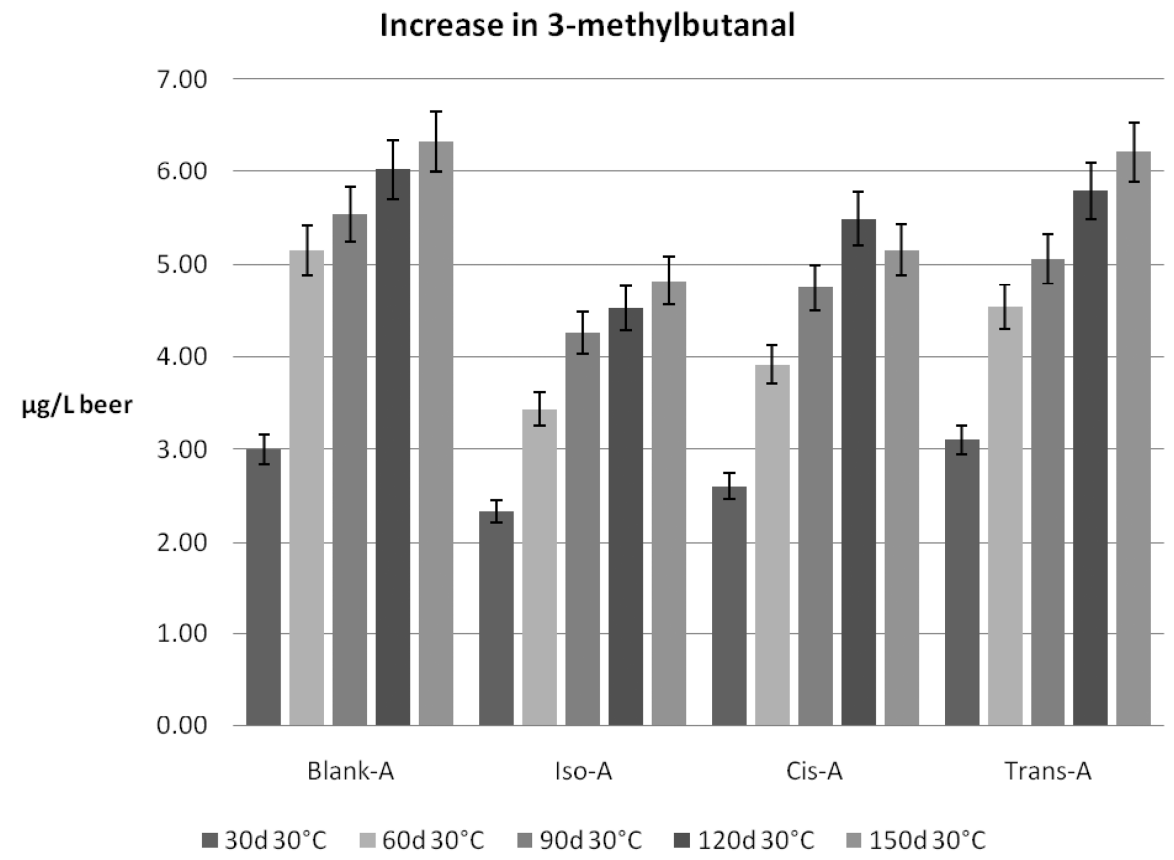

Fig. 12. Comparison of the increase in 3-methylbutanal during forced ageing $\left(30^{\circ} \mathrm{C}\right)$ as a function of the bittering regime of the pilot beers derived from brew A. Error bars represent the $95 \%$ confidence interval determined by Student's $t$-test; $\mathrm{n}=6$.

Table IV. Average values (standard deviation in parentheses; $\mathrm{n}=6$ ) of the concentrations of aldehydes $(\mu \mathrm{g} / \mathrm{L})$ in fresh and forced aged $\left(30^{\circ} \mathrm{C}\right)$ pilot beer samples, derived from the same basic 2-hL brew, prepared with malt B.

\begin{tabular}{|c|c|c|c|c|c|c|c|c|c|c|c|}
\hline Beer & Sample ${ }^{a}$ & $\begin{array}{l}\text { 2-Methyl- } \\
\text { propanal }\end{array}$ & $\begin{array}{l}\text { 2-Methyl- } \\
\text { butanal }\end{array}$ & $\begin{array}{l}\text { 3-Methyl- } \\
\text { butanal }\end{array}$ & $\begin{array}{l}\text { Methi- } \\
\text { onal }\end{array}$ & $\begin{array}{l}\text { Benzal- } \\
\text { dehyde }\end{array}$ & $\begin{array}{l}\text { Phenylac- } \\
\text { etaldehyde }\end{array}$ & Furfural & Hexanal & $t$-2-Nonenal & $\begin{array}{c}\text { Sum aldehyde } \\
\text { markers }\end{array}$ \\
\hline \multirow[t]{6}{*}{ Blank-B } & fresh & $7.1(0.1)$ & $3.1(0.0)$ & 5) & $4.9(0.6)$ & $2.8(0.1)$ & $10.5(0.7)$ & $13.0(0.3)$ & $1.1(0.0)$ & $0.03(0.00)$ & $51.5(2.5)$ \\
\hline & $30 \mathrm{~d} 30^{\circ} \mathrm{C}$ & $23.5(1.0)$ & $5.8(0.2)$ & $13.8(0.0)$ & $8.6(0.8)$ & $2.9(0.0)$ & $17.2(0.5)$ & $130.9(5.0)$ & $1.6(0.1)$ & $0.08(0.00)$ & $204.4(7.7)$ \\
\hline & $60 \mathrm{~d} 30^{\circ} \mathrm{C}$ & $35.9(1.2)$ & $8.6(0.1)$ & $19.8(0.7)$ & $12.7(0.1)$ & $3.5(0.1)$ & $23.6(0.1)$ & $27.9(7.5)$ & $1.9(0.1)$ & $0.11(0.00)$ & $334.1(9.9)$ \\
\hline & $90 \mathrm{~d} 30^{\circ} \mathrm{C}$ & $42.8(1.0)$ & $10.0(0.1)$ & $21.0(0.4)$ & $13.4(0.8)$ & $3.3(0.1)$ & $27.7(0.4)$ & $305.8(7.5)$ & $2.2(0.1)$ & $0.12(0.00)$ & $426.2(10.4)$ \\
\hline & $120 \mathrm{~d} 30^{\circ} \mathrm{C}$ & $46.5(1.2)$ & $11.3(0.2)$ & $22.4(1.1)$ & $13.6(0.3)$ & $3.3(0.1)$ & $27.2(0.7)$ & $366.3(10.6)$ & $2.2(0.1)$ & $0.13(0.01)$ & $492.9(14.2)$ \\
\hline & $150 \mathrm{~d} 30^{\circ} \mathrm{C}$ & $52.1(1.9)$ & $13.0(0.5)$ & $26.2(0.7)$ & $14.7(0.4)$ & $3.8(0.1)$ & $29.2(0.9)$ & $394.4(17.5)$ & $2.7(0.1)$ & $0.13(0.00)$ & $536.2(22.1)$ \\
\hline \multirow[t]{6}{*}{ Iso-B } & fresh & $2.8(0.0)$ & $3.3(0.2)$ & $13.5(0.3)$ & $4.1(0.2)$ & $1.9(0.1)$ & $8.9(0.1)$ & $14.1(0.7)$ & $1.2(0.0)$ & $0.01(0.00)$ & 49.8 (1.6) \\
\hline & $30 \mathrm{~d} 30^{\circ} \mathrm{C}$ & $20.5(0.6)$ & $5.7(0.1)$ & $19.3(0.4)$ & $10.9(0.4)$ & $2.2(0.1)$ & $14.2(0.3)$ & $108.6(3.2)$ & $1.9(0.0)$ & $0.06(0.00)$ & $183.3(5.0)$ \\
\hline & & & $7.3(0.3)$ & $22.1(0.9)$ & $12.9(0.1)$ & $2.5(0.1)$ & $16.5(0.2)$ & 1625050 & $2.3(0.1)$ & $0.07(0.00)$ & $254.6(9.1)$ \\
\hline & $90 \mathrm{~d} 30^{\circ} \mathrm{C}$ & $41.0(2.2)$ & $9.8(0.3)$ & $26.5(0.8)$ & $16.2(0.4)$ & $2.7(0.1)$ & $20.7(0.3)$ & $259.5(9.0)$ & $2.8(0.1)$ & $0.10(0.00)$ & $379.3(13.2)$ \\
\hline & $120 \mathrm{~d} 30^{\circ} \mathrm{C}$ & $44.1(0.5)$ & $11.0(0.3)$ & $27.7(0.3)$ & $17.1(0.3)$ & $2.5(0.1)$ & $21.7(0.4)$ & $301.4(3.8)$ & $2.7(0.0)$ & $0.10(0.01)$ & $428.3(5.7)$ \\
\hline & $150 \mathrm{~d} 30^{\circ} \mathrm{C}$ & $48.7(0.7)$ & $12.7(0.2)$ & $30.4(0.2)$ & 18.5 & $2.9(0.1)$ & $21.5(0.5)$ & $366.0(12.8)$ & $2.9(0.1)$ & $0.11(0.01)$ & 503.9 (15.7) \\
\hline \multirow[t]{6}{*}{ Cis-B } & fresh & $7.3(0.2)$ & $3.7(0.1)$ & $10.2(0.5)$ & $7.8(0.2)$ & $1.7(0.1)$ & $9.6(0.2)$ & $12.4(0.4)$ & $1.5(0.2)$ & $0.04(0.00)$ & $54.1(2.0)$ \\
\hline & $30 \mathrm{~d} 30^{\circ} \mathrm{C}$ & $26.8(0.1)$ & $5.6(0.0)$ & $14.0(0.4)$ & $12.6(0.2)$ & $2.0(0.1)$ & $15.6(0.4)$ & $103.8(1.6)$ & $2.2(0.0)$ & $0.09(0.00)$ & $182.6(2.9)$ \\
\hline & $60 \mathrm{~d} 30^{\circ} \mathrm{C}$ & $37.9(0.7)$ & $7.8(0.2)$ & $17.4(0.6)$ & $16.2(0.7)$ & $2.2(0.2)$ & $17.5(0.3)$ & $177.1(2.8)$ & $2.7(0.1)$ & $0.11(0.01)$ & $278.9(5.6)$ \\
\hline & $90 \mathrm{~d} 30^{\circ} \mathrm{C}$ & $41.1(1.3)$ & $9.6(0.2)$ & $20.6(0.9)$ & $19.6(1.1)$ & $2.1(0.1)$ & $21.6(1.2)$ & $236.0(11.5)$ & $2.7(0.1)$ & $0.13(0.02)$ & $353.5(16.4)$ \\
\hline & $120 \mathrm{~d} 30^{\circ} \mathrm{C}$ & $47.6(1.5)$ & $11.1(0.1)$ & $23.8(0.5)$ & $21.2(1.2)$ & $2.4(0.1)$ & $22.7(1.3)$ & 302.7 (7.6) & $2.9(0.0)$ & $0.14(0.00)$ & $434.3(12.4)$ \\
\hline & $150 \mathrm{~d} 30^{\circ} \mathrm{C}$ & $51.0(1.5)$ & $12.7(0.2)$ & $26.0(0.6)$ & $23.2(1.0)$ & $2.3(0.1)$ & $23.7(0.6)$ & $356.1(3.5)$ & $3.3(0.0)$ & $0.14(0.01)$ & $498.5(7.5)$ \\
\hline \multirow{6}{*}{ Trans-B } & fresh & 8.7 ( & $3.3(0.2)$ & 9.5( & $5.2(0.4)$ & $2.7(0.1)$ & $10.4(0.5)$ & 13.5( & $1.5(0.0)$ & $0.04(0.00)$ & $54.7(2.2)$ \\
\hline & $30 \mathrm{~d} 30^{\circ} \mathrm{C}$ & $24.6(1.0)$ & $6.1(0.2)$ & $14.6(0.6)$ & $12.0(0.3)$ & $2.9(0.1)$ & $15.7(0.8)$ & $116.0(4.2)$ & $2.2(0.1)$ & $0.09(0.00)$ & $194.1(7.3)$ \\
\hline & $60 \mathrm{~d} 30^{\circ} \mathrm{C}$ & $34.3(2.2)$ & $8.1(0.6)$ & $18.1(1.3)$ & $15.7(1.5)$ & $3.2(0.3)$ & $22.8(1.5)$ & $191.3(9.3)$ & $2.6(0.1)$ & $0.11(0.00)$ & $296.3(17.0)$ \\
\hline & $90 \mathrm{~d} 30^{\circ} \mathrm{C}$ & $41.5(0.3)$ & $9.8(0.1)$ & $20.4(0.4)$ & $15.9(1.3)$ & $3.1(0.1)$ & $24.3(0.3)$ & $262.3(11.8)$ & $2.8(0.1)$ & $0.14(0.01)$ & 380.1 (14.5) \\
\hline & $120 \mathrm{~d} 30^{\circ} \mathrm{C}$ & $45.0(0.7)$ & $10.8(0.1)$ & $21.6(0.5)$ & $16.1(0.1)$ & $3.3(0.1)$ & $24.3(0.5)$ & $299.4(8.5)$ & $2.9(0.2)$ & $0.14(0.00)$ & $423.6(10.7)$ \\
\hline & $150 \mathrm{~d} 30^{\circ} \mathrm{C}$ & $50.4(0.9)$ & $12.4(0.1)$ & $24.7(1.0)$ & $19.6(0.0)$ & $3.7(0.4)$ & $25.2(0.5)$ & $365.2(9.6)$ & $3.2(0.2)$ & $0.15(0.01)$ & $504.4(12.7)$ \\
\hline
\end{tabular}

${ }^{a}$ Fresh: fresh beer sample; $30 \mathrm{~d} 30^{\circ} \mathrm{C}, 60 \mathrm{~d} 30^{\circ} \mathrm{C}, 90 \mathrm{~d} 30^{\circ} \mathrm{C}, 120 \mathrm{~d} 30^{\circ} \mathrm{C}, 150 \mathrm{~d} 30^{\circ} \mathrm{C}$ : beer sample aged for respectively $30,60,90,120$, and 150 days at $30^{\circ} \mathrm{C}$.

with the scientific findings reported by Hashimoto and Eshima $^{18}$ stating that beer brewed without hops hardly develops any typical stale flavour, even after prolonged storage. According to these authors, the development of aldehydes was suppressed by decreasing the levels of isohumulones in beer.

In order to identify other critical factors related to the flavour stability of beer in terms of the formation of these branched aldehydes, quantitative headspace SPME GCMS profiling of 2-methylpropanal, 2-methylbutanal and 3-methylbutanal was thereupon performed on the fresh and forced aged $\left(30,60,90,120\right.$ and 150 days at $30^{\circ} \mathrm{C}$ in the dark) identically brewed and bittered beer samples Iso-B, Cis- $\mathrm{B}$, Trans- $\mathrm{B}$, and Blank- $\mathrm{B}$, derived from the basic brew obtained with malt $\mathrm{B}$, of which the results are summarised in Table IV. Formation of these aldehydes 


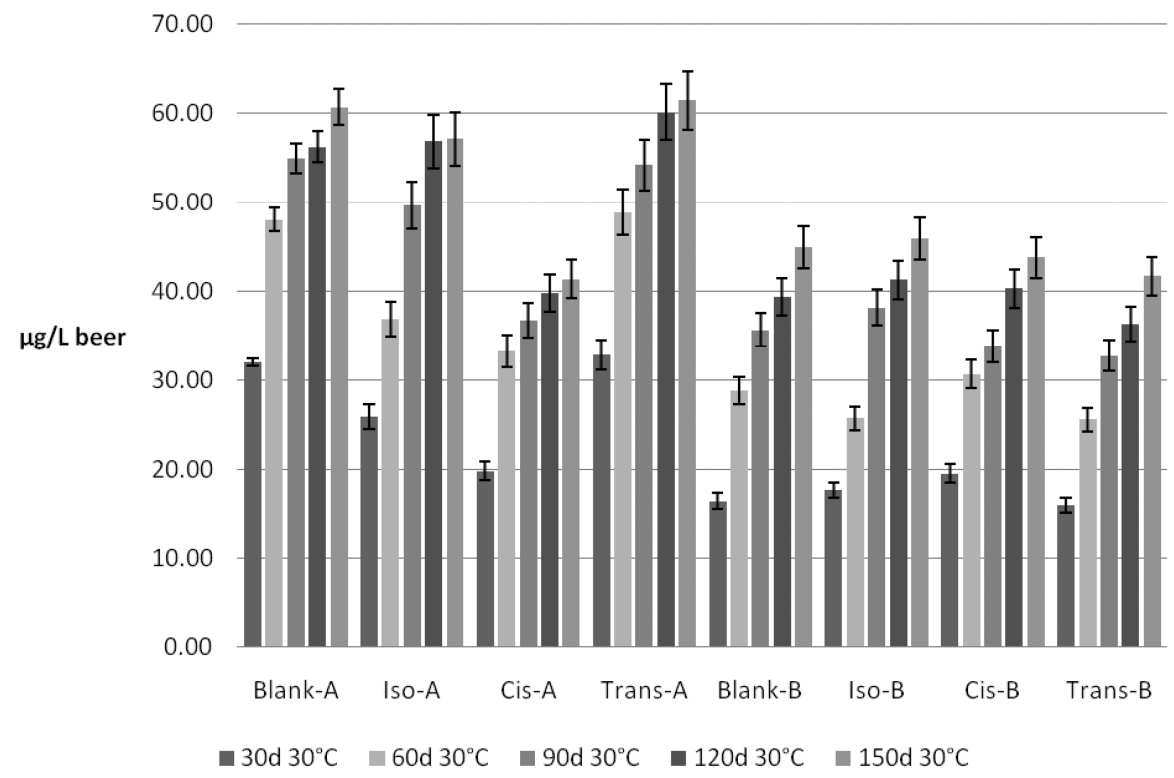

Fig. 13. Comparison of the increase in 2-methylpropanal during forced ageing $\left(30^{\circ} \mathrm{C}\right)$ as a function of the malt used for production of the pilot beers. The differently bittered pilot beers were derived from two identical basic $2 \mathrm{hL}$-brews, produced with malt $\mathrm{A}$ and $\mathrm{B}$, respectively. Error bars represent the $95 \%$ confidence interval determined by Student's $t$-test; $\mathrm{n}=6$.

\section{Increase in 2-methylbutanal in identically brewed pilot beers using different malts}

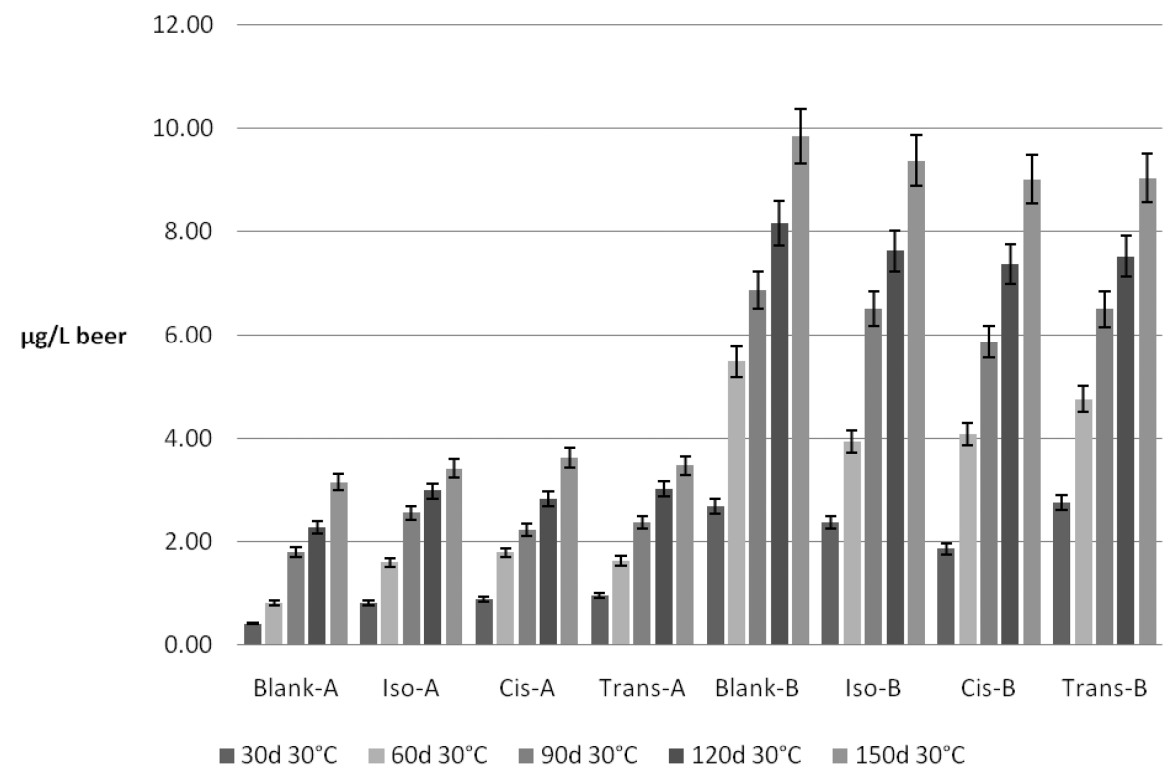

Fig. 14. Comparison of the increase in 2-methylbutanal during forced ageing $\left(30^{\circ} \mathrm{C}\right)$ as a function of the malt used for production of the pilot beers. The differently bittered pilot beers were derived from two identical basic $2 \mathrm{hL}$-brews, produced with malt $\mathrm{A}$ and $\mathrm{B}$, respectively. Error bars represent the 95\% confidence interval determined by Student's $t$-test; $\mathrm{n}=6$.

upon ageing as a function of the different bittering applied, as well as the malt used for beer production, is depicted in Fig. 13, 14 and 15 for 2-methylpropanal, 2-methylbutanal and 3-methylbutanal respectively. When comparing the increase in the concentration of these branched aldehydes during forced ageing of the B-beers, again no differences between the unhopped and the bittered beers were observed, confirming our findings for brew A, i.e., that no relationship can be demonstrated between the degradation of trans-iso- $\alpha$-acids and the formation of 2-methylpropanal, 2-methylbutanal and 3-methylbutanal upon ageing. However, all B-beers did differ in 


\section{Increase in 3-methylbutanal in identically brewed pilot beers using}

different malts

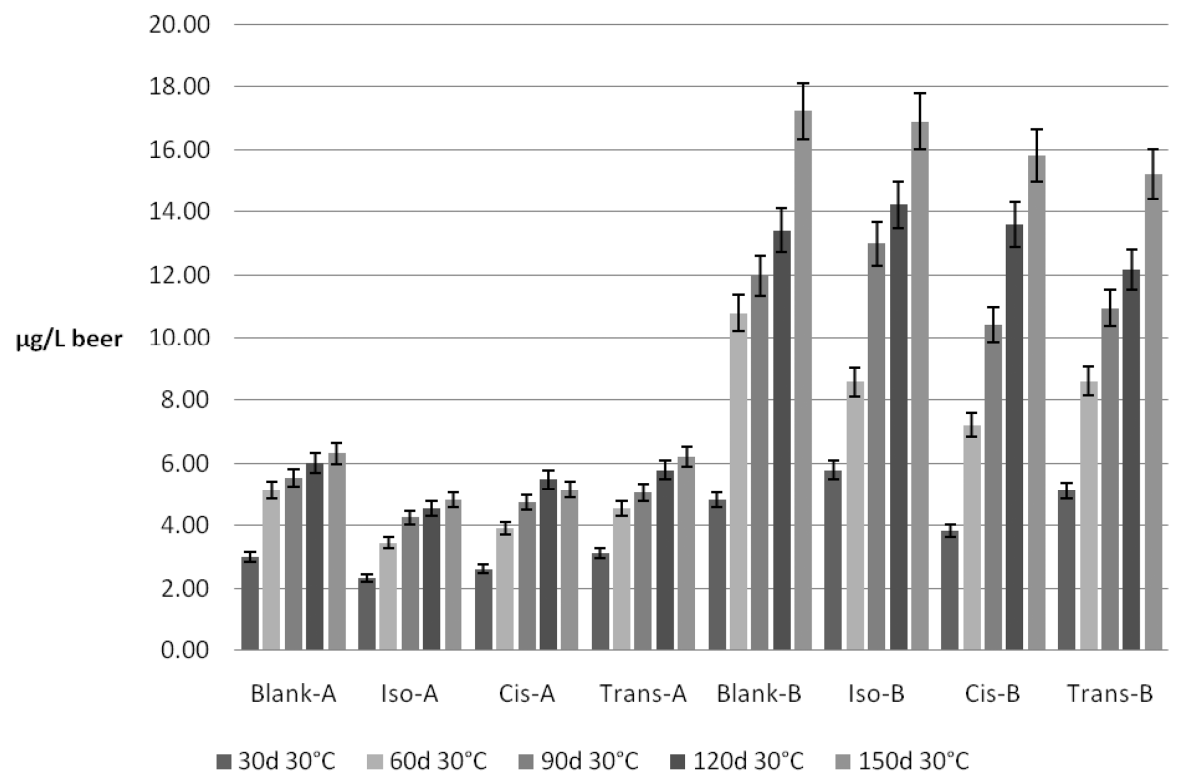

Fig. 15. Comparison of the increase in 3-methylbutanal during forced ageing $\left(30^{\circ} \mathrm{C}\right)$ as a function of the malt used for production of the pilot beers. The differently bittered pilot beers were derived from two identical basic $2 \mathrm{hL}$-brews, produced with malt $\mathrm{A}$ and $\mathrm{B}$, respectively. Error bars represent the $95 \%$ confidence interval determined by Student's $t$-test; $\mathrm{n}=6$.

their branched aldehyde profile from their corresponding A-beer, obtained from an identical brewing trial but derived from a different malt. Except for 2-methylpropanal, the fresh B-beers contained higher levels of the branched aldehydes compared with the fresh A-beers: 3.1-3.7 $\mu \mathrm{g} / \mathrm{L}$ vs. $1-2.5 \mu \mathrm{g} / \mathrm{L}$ for 2 -methylbutanal, and $9-13.5 \mu \mathrm{g} / \mathrm{L}$ vs. 5.7-6.6 $\mu \mathrm{g} / \mathrm{L}$ for 3-methylbutanal, respectively (Table III vs. IV). The increase of these branched aldehydes upon storage also appeared to a significantly larger extent than in the beers derived from malt A. At the end of the experimental ageing period $\left(150\right.$ days at $\left.30^{\circ} \mathrm{C}\right)$ the concentration of 2-methylbutanal in the B-beers augmented with 9-10 $\mu \mathrm{g} / \mathrm{L}$ vs. $3-4 \mu \mathrm{g} / \mathrm{L}$ in the A-beers (Fig. 14). Likewise, more 3 -methylbutanal was formed during ageing in the beers derived from malt $\mathrm{B}$ than in the corresponding beers derived from malt A, respectively $14-18 \mu \mathrm{g} / \mathrm{L}$ and 5-6 $\mu \mathrm{g} / \mathrm{L}$ after 150 days at $30^{\circ} \mathrm{C}$ (Fig. 15). Notwithstanding the different bittering of these eight studied beers, these findings illustrate the influence of the malt type on the branched aldehyde content and storage-induced formation, as the beers were derived from two basic brews, identically brewed, except for the type of malt used.

\section{Evaluation of the influence of the malt on the aldehyde content of fresh and aged beer}

The storage-induced bitter acids decomposition is unlikely to contribute to branched aldehyde formation upon beer ageing, as illustrated by the results described above. On the other hand, it has been shown that only the use of another malt accounted for different levels of the branched aldehydes in fresh and aged identically brewed beers. Seeing that these branched aldehydes, 2-methylpropanal, 2-methylbutanal, and 3-methylbutanal, are also
Strecker degradation aldehydes, more Strecker aldehydes (methional, phenylacetaldehyde and benzaldehyde) were selected for analysis, in order to underpin the preliminary conclusion about the importance of the malt and the brewing process itself regarding the flavour stability of the studied beers. In total, nine marker aldehydes were selected for this purpose, including the heat-load indicator furfural and lipid oxidation aldehydes (hexanal and trans2-nonenal). The results of the quantitative headspace SPME GC-MS profiling, performed on fresh and forced aged $\left(30,60,90,120\right.$ and 150 days at $30^{\circ} \mathrm{C}$ in the dark) beer samples of both brews, obtained with malt A and B, are summarised in Table III and IV, respectively. When comparing the aldehyde profiles of the fresh beers, the levels of nearly all aldehydes were higher in the fresh beers derived from malt B. In all beers, also the Strecker aldehydes methional and phenylacetaldehyde increased during ageing, whereas the lipid oxidation aldehydes showed a minor increase on a quantitative basis, but a considerable increase on a relative basis. The increase of furfural, not necessarily an off-flavour but an indicator of flavour deterioration, had the largest impact on the increase of the sum of the aldehyde markers during ageing. When comparing the increase of methional (Fig. 16), phenylacetaldehyde (Fig. 17), and furfural during storage as a function of the different malt type, the beers derived from malt B displayed a significantly larger increase, which is in accordance with our previous findings, demonstrating the influence of the malt quality on the aldehyde content of the aged beers. With these supplementary analyses of marker aldehydes in the fresh and aged beers, it has been confirmed that the explanation of aldehyde formation upon beer ageing lies in the difference 


\section{Increase in methional in identically brewed pilot beers using different}

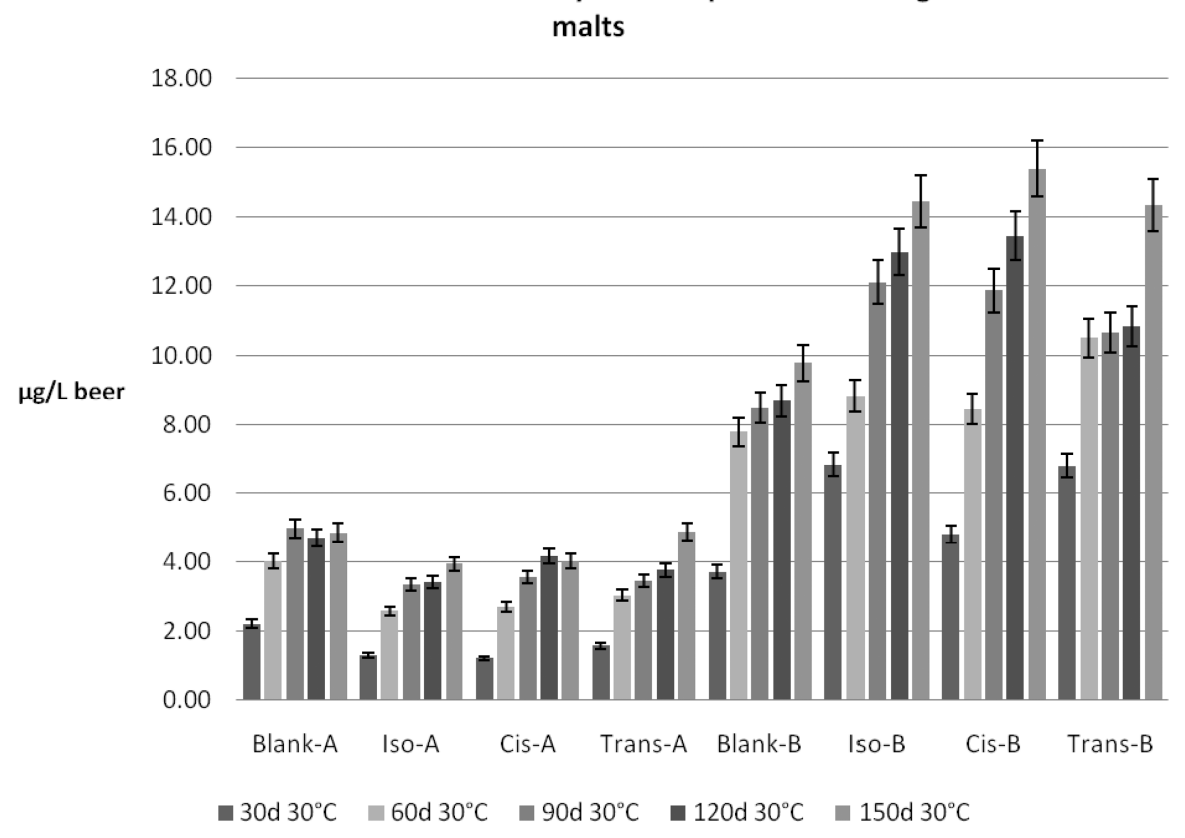

Fig. 16. Comparison of the increase in methional during forced ageing $\left(30^{\circ} \mathrm{C}\right)$ as a function of the malt used for production of the pilot beers. The differently bittered pilot beers were derived from two identical basic $2 \mathrm{hL}$-brews, produced with malt A and B, respectively. Error bars represent the $95 \%$ confidence interval determined by Student's $t$-test; $\mathrm{n}=6$.

of the malt used in the brewing process. These results make it likely to conclude that factors related to the brewing process and the beer matrix such as malt and wort quality, are probably the most important factors regarding the flavour stability of beer. In order to subscribe this point of view, the impact of the malt on the flavour stability of beer was additionally estimated by examining the aldehyde content of the two malt samples used for beer production in this study.

\section{Evaluation of the malt aldehyde content as related to the flavour stability of beer}

The strong influence of malt composition on final beer quality and beer flavour stability is generally acknowledged ${ }^{6,8,13,16}$. Most of the volatile aldehydes formed or released upon beer storage, and recognised as one of the main causes of beer flavour deterioration ${ }^{4,45,51}$, indeed preexist abundantly in malt, and vary significantly between different malt types ${ }^{8}$. With extremely powerful hyphenated analytical techniques, such as selected ion flow tube mass spectrometry (SIFT-MS) and headspace SPME GCMS, malted barley cultivars were differentiated on the basis of the presence of marker aldehydes, associated with beer flavour stability, in their headspace profile ${ }^{8}$. As such, it was assumed that the staling potential of finished beer is largely determined by the type of malt used in the brewing process ${ }^{8,15,42,46,47}$. With the experiments in the present study, we provide further evidence that malt plays an important role in beer flavour deterioration during storage. In this context, the content of marker aldehydes present in the two different malt samples used in this study was determined and were related to the aldehyde profiles of the fresh and forced aged beers derived thereof. The results of the quantitative headspace SPME GC-MS profiling, performed on both malt samples, are summarised in Table V, which are the mean values of two measurements with coefficients of variation situated between $0.2 \%$ and $25 \%$. The differences in the aldehyde profiles of the malt samples A and B are obvious from the data depicted in this Table. The levels of all aldehydes are higher in malt $\mathrm{B}$ than in malt A, and these different aldehyde profiles were reflected in the aldehyde content of the final corresponding fresh and aged beers. As such, the impact of the malt variety as well as of the different malting conditions applied by the two different malting plants on the aldehyde content of fresh and forced aged beers was demonstrated and considered significant in terms of the influence on the flavour stability of the experimental beers. Many of these compounds are described in the literature as key odorants in barley and malted barley ${ }^{7,12,48}$, and as illustrated here, both the organoleptic quality of beers as well as their flavour stability during ageing, are affected by them. Consequently, knowledge of these variations in malt aldehyde content is indispensable for brewers in view of quality control, selection of the appropriate malt cultivar and malting conditions, and objective assessment of the flavour stability of the processed beer. In fact, each modern brewery that aims at a pleasant and consistent beer flavour has to take appropriate measures from the onset of the brewing process by selecting high-quality malt. In this context, the role of the malt processing conditions as well as of bound aldehydes that might be released during ageing of the final beer, are certainly subjects for further investigations. 


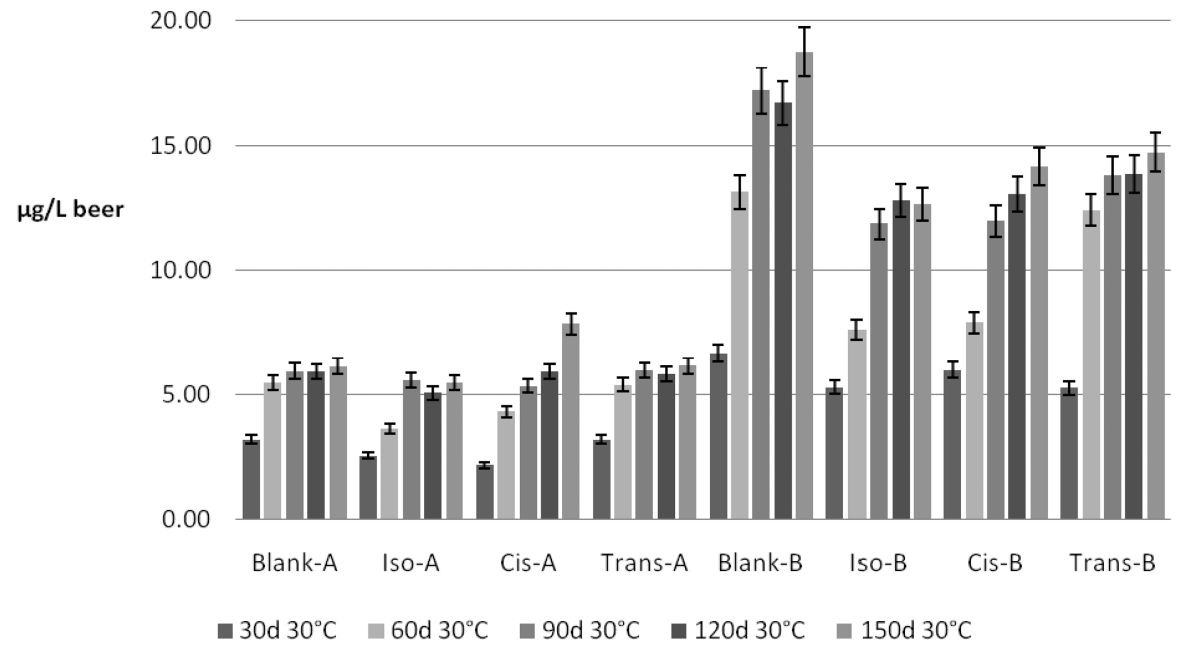

Fig. 17. Comparison of the increase in phenylacetaldehyde during forced ageing $\left(30^{\circ} \mathrm{C}\right)$ as a function of the malt used for production of the pilot beers. The differently bittered pilot beers were derived from two identical basic $2 \mathrm{hL}$-brews, produced with malt $\mathrm{A}$ and $\mathrm{B}$, respectively. Error bars represent the $95 \%$ confidence interval determined by Student's $t$-test; $\mathrm{n}=6$.

Table V. Average values (standard deviation in parentheses; $n=6$ ) of the concentrations of volatile aldehyde markers ( $\mu \mathrm{g} / \mathrm{kg}$ malt) measured in the headspace of the malts used in this study.

\begin{tabular}{lcc}
\hline & \multicolumn{2}{c}{ Malt sample } \\
\cline { 2 - 3 } Component & A & B \\
\hline Hexanal & $834(27)$ & $1010(41)$ \\
trans-2-Nonenal & $58(2)$ & $74(3)$ \\
2-Methylpropanal & $1885(5)$ & $2311(39)$ \\
2-Methylbutanal & $952(19)$ & $1119(111)$ \\
3-Methylbutanal & $3674(120)$ & $4197(192)$ \\
Methional & $224(7)$ & $377(5)$ \\
Phenylacetaldehyde & $736(31)$ & $853(35)$ \\
Benzaldehyde & $86(23)$ & $93(10)$ \\
Furfural & $404(63)$ & $416(1)$ \\
\hline
\end{tabular}

\section{CONCLUSIONS}

In conclusion, in spite of the distinct conversion of trans-iso- $\alpha$-acids, especially demonstrated in the beers bittered post-fermentation with our own extract containing nearly exclusively trans-iso- $\alpha$-acids, the trans-specific degradation could not be linked to the formation of 2methylpropanal, 2-methylbutanal and 3-methylbutanal, all aldehydes attributed to the hop derived bitter acids degradation during storage in the literature ${ }^{18,19,33}$. Clearly, judging from the amount of branched aldehydes formed in both the unhopped and the bittered beer matrices, the pathway proposed for the formation of these volatile carbonyl compounds as beer ages, does not account for the levels of trans-iso- $\alpha$-acids converted. The oxidative degradation of isohumulones to volatile off-flavour carbonyl compounds, such as 2-methylpropanal, is found to be only a minor reaction pathway under these conditions, unlike earlier data shown in the literature ${ }^{18,19,33}$. Our findings seem to indicate that the storage-induced conversion of in particular trans-iso- $\alpha$-acids can indeed be explained by the mechanisms as proposed by Hofmann and his coworkers ${ }^{22,27,28}$. This implies that the bitter tasting trans-iso$\alpha$-acids, vulnerable to degradation, not only adversely affect the beer flavour upon ageing by a significant decrease in the bitterness intensity, but also by a quality change towards a lingering and harsh bitterness, by the formation of non-volatile cyclic transformation products. This would indicate that the lingering effect develops less in beers bittered with practically exclusively cis-iso- $\alpha$-acids, as were made in this study. Nevertheless, the stale flavour development during storage, where the levels of marker aldehydes measured in the beer matrices account for, was irrespective of the bitter principles present. This means that a beer exclusively bittered with $c i s$-iso- $\alpha$-acids, exhibiting superior stability towards degradation compared with their trans-counterparts, is not necessarily more flavour stable. Actually, the explanation of aldehyde formation upon beer ageing was found in the malt used for brewing, irrespective of the mode of bittering. These findings on the routes that might account for the levels of aldehydes occurring in beer during storage, make it likely to conclude that critical factors related to the brewing process and the beer matrix, such as malt and wort quality, are probably the most important factors regarding the flavour stability of beer. Accordingly, knowledge of the variations in the malt headspace profiles among various malted barley types, varieties, harvest years, and processing conditions is of great interest to the commercial user. By selection of high-quality raw materials and the application of a technologically advanced and controlled production process, each modern brewery can then aim at a pleasant and consistent beer flavour ${ }^{1}$. 


\section{REFERENCES}

1. Aerts, G. and van Waesberghe, J., Innovative wort production in relation to 21st century wort boiling and optimised beer flavour quality and stability. Proceedings of the European Brewery Convention Congress, Venice, 2007, Fachverlag Hans Carl: Nürnberg, Germany, CD ROM 2007, Contribution 56.

2. Araki, S., Takashio, M. and Shinotsuka, K., A new parameter for determination of the extent of staling in beer. J. Am. Soc. Brew. Chem., 2002, 60, 26-30.

3. Bamforth, C. W., A critical control point analysis for flavor stability of beer. Tech. Q. Master Brew. Assoc. Am., 2004, 41(2), 97-103.

4. Bamforth, C. W., The science and understanding of the flavour stability of beer: a critical assessment. Brauwelt Int., 1999, II, 98-110.

5. Benitez, J. L., Forster, A., De Keukeleire, D., Moir, M., Sharpe, F. R., Verhagen, L. C. and Westwood, K. T., European Brewery Convention Manual of Good Practice: Hops and Hop Products, Fachverlag Hans Carl, Nürnberg, Germany, 1997.

6. Boivin, P., A review of pro- and anti-oxidant of malt. Monograph 31 of the European Brewery Convention Symposium 'Flavour and Flavour Stability', Nancy, 2001, Fachverlag Hans Carl: Nürnberg, Germany, CD ROM 2001, Contribution 1.

7. Cramer, A. C. J., Mattinson, D. S., Fellman, J. K. and Baik, B. K., Analysis of volatile compounds from various types of barley cultivars. J. Agric. Food Chem., 2005, 53(19), 7526-7531.

8. De Clippeleer, J., Van Opstaele, F., Vercammen, J., Francis, G. J., De Cooman, L. and Aerts, G., Real-time profiling of volatile malt aldehydes using selected ion flow tube mass spectrometry (SIFT-MS). LCGC North Am., 2010, 28(5), 1-9.

9. De Cooman, L., Aerts, G., De Rouck, G., Syryn, E., Van Opstaele, F., Goiris, K., De Ridder, M., Joos, P. and De Keukeleire, D., Replacement of kettle hops with (reduced) isomerised hop extracts: implications for beer bitterness and flavour stability. Proceedings of the European Brewery Convention Congress, Dublin, 2003, Fachverlag Hans Carl: Nürnberg, Germany, CD ROM 2003, Contribution 24.

10. De Cooman, L., Aerts, G., Overmeire, H. and De Keukeleire, D., Alterations of the profiles of iso- $\alpha$-acids during beer ageing, marked instability of trans-iso- $\alpha$-acids and implications for beer bitterness consistency in relation to tetrahydroiso- $\alpha$-acids. $J$. Inst. Brew., 2000, 106(3), 169-178.

11. De Cooman, L., Aerts G., Witters, A., De Ridder, M., Boeykens, A., Goiris, K. and De Keukeleire, D., Comparative study of the stability of iso- $\alpha$-acids, dihydroiso- $\alpha$-acids, and tetrahydroiso- $\alpha$ acids during beer ageing. Proceedings of the European Brewery Convention Congress, Budapest, 2001, Fachverlag Hans Carl: Nürnberg, Germany, CD ROM 2001, Contribution 60.

12. Fickert, B. and Schieberle, P., Identification of the key odorants in barley malt (caramalt) using GC/MS techniques and odour dilution analyses. Nahrung, 1998, 42, S.371-375.

13. Gastl, M., Spieleder, E., Hermann, M., Thiele, F., Burberg, F., Kogin, A., Ikeda, H., Back, W. and Narziss, L., The influence of malt quality and malting technology on the flavour stability of beer. Monatsschr. Brauwiss., 2006, 59, 163-174.

14. Grönqvist, A., Siirilä, J., Virtanen, H., Home, S. and Pajunen, E., Carbonyl compounds during beer production and in beer. Proceedings of the European Brewery Convention Congress, Oslo, IRL Press Oxford, 1993, pp. 421-428.

15. Guido, L. F., Boivin, P., Benismail, N., Gonçalves, C. R. and Barros, A. A., An early development of the nonenal potential in the malting process. Proceedings of the European Brewery Convention Congress, Prague, 2005, Fachverlag Hans Carl: Nürnberg, Germany, CD ROM 2005, Contribution 77.

16. Guido, L. F., Curto, A. F., Boivin, P., Benismail, N., Gonçalves, C. R. and Barros, A. A., Correlation of malt quality parameters and beer flavor stability: multivariate analysis. J. Agric. Food Chem., 2007, 55, 728-733.

17. Hashimoto, N., Melanoidin-mediated oxidation; a greater involvement in flavor staling. Techn. Rep. Kirin, 1988, 31, 19-32.
18. Hashimoto, N. and Eshima, T., Oxidative degradation of isohumulones in relation to flavour stability of beer. J. Inst. Brew., 1979, 85, 136-140.

19. Hashimoto, N. and Eshima, T., Composition and pathway of formation of stale aldehydes in bottled beer. J. Am. Soc. Brew. Chem., 1977, 35, 145-149.

20. Hashimoto, N. and Kuroiwa, Y., Proposed pathways for the formation of volatile aldehydes during storage of bottled beer. $J$. Am. Soc. Brew. Chem., 1975, 33, 104-111.

21. Heyerick, A., Huvaere, K., De Keukeleire, D. and Forbes, M. D. E., Fate of flavins in sensitized photodegradation of isohumulones and reduced derivatives: studies on formation of radicals via EPR combined with detailed product analyses. Photochem. Photobiol. Sci., 2005, 4, 412-419.

22. Hofmann, T. and Intelmann, D., The (in)stability of the beer's bitter taste - Elucidation of the mechanisms involved in transiso-alpha-acid degradation and formation of bitter off-taste compounds upon beer storage. European Brewery Convention Congress, Hamburg, Germany, 2009. Contribution L29.

23. Hughes, P. S. and Marinova, G., Variations in iso-alpha-acids distribution and behaviour of different products. Brew. Guardian, 1997, 126(3), 26-29.

24. Hughes, P. S., Menneer, I. D., Walters, M. T. and Marinova, G., Differential behaviour of $c i s$ - and trans-iso- $\alpha$-acids. Proceedings of the European Brewery Convention Congress, Maastricht, IRL Press: Oxford, 1997, pp. 230-238.

25. Huvaere, K., Andersen, M. L., Olsen, K., Skibsted, L. H., Heyerick, A. and De Keukeleire, D., A common oxidative degradation pathway for iso- $\alpha$-acids and hydrogenated iso- $\alpha$-acids in beer: evidence from electrolysis and radical trapping followed by electron spin resonance analysis. Proceedings of the European Brewery Convention Congress, Dublin, 2003, Fachverlag Hans Carl: Nürnberg, Germany, CD ROM 2003, Contribution 86 .

26. Huvaere, K., Sinnaeve, B., Van Bocxlaer, J. and De Keukeleire, D., Photooxidative degradation of beer bittering principles: product analysis with respect to lightstruck flavour formation. Photochem. Photobiol. Sci., 2004, 3, 854-858.

27. Intelmann, D., Demmer, O., Desmer, N. and Hofmann, T., ${ }^{18} \mathrm{O}$ stable isotope labeling, quantitative model experiments, and molecular dynamics simulation studies on the trans-specific degradation of the bitter tasting iso- $\alpha$-acids of beer. J. Agric. Food Chem., 2009, 57, 11014-11023.

28. Intelmann, D., Kummerlöwe, G., Haseleu, G., Desmer, N., Schulze, K., Fröhlich, R., Frank, O., Luy, B. and Hofmann, T., Structures of storage-induced transformation products of the beer's bitter principles, revealed by sophisticated NMR spectroscopic and LC-MS techniques. Chem. Eur. J., 2009, 15, 1304713058.

29. Institute of Brewing, Analysis Committee of the IoB. Recommended Methods of Analysis. Institute of Brewing: London, 1997.

30. Jaskula, B., Goiris, K., De Rouck, G., Aerts, G. and De Cooman, L., Enhanced quantitative extraction and HPLC determination of hop and beer bitter acids. J. Inst. Brew., 2007, 113(4), 381-390.

31. Jaskula, B., Kafarski, P., Aerts, G. and De Cooman, L., A kinetic study on the isomerisation of hop $\alpha$-acids. J. Agric. Food Chem., 2008, 56, 6408-6415.

32. Jaskula, B., Syryn, E., Goiris, K., De Rouck, G., Van Opstaele, F., De Clippeleer, J., Aerts, G. and De Cooman, L., Hopping technology in relation to beer bitterness consistency and flavor stability. J. Am. Soc. Brew. Chem., 2007, 65(1), 38-46.

33. Kaneda, H., Kano, Y., Osawa, T., Kawakishi, S. and Kamada, K., The role of free radicals in beer oxidation. J. Am. Soc. Brew. Chem., 1989, 47(2), 49-53.

34. Khatib, A., Wilson, E. G., Supardi, M. and Verpoorte, R., Isolation of individual hop iso- $\alpha$-acids stereoisomers by $\beta$-cyclodextrin. Food Chem., 2010, 119, 354-357.

35. Khatib, A., Wilson, E. G., Zhang, H. R., Supardi, M. and Verpoorte, R., The application of $\beta$-cyclodextrin to separate cis- 
from trans-iso- $\alpha$-acids in an isomerized hop extract. J. Am. Soc. Brew. Chem., 2010, 68(1), 15-20.

36. King, B. M. and Duineveld, C. A. A., Changes in bitterness as beer ages naturally. Food Qual. Prefer., 1999, 10, 315-324.

37. Laws, D. R. J. and Peppard, T. L., The stability of flavour constituents in alcoholic beverages. Food Chem., 1982, 9, 131-146.

38. Malfliet, S., Van Opstaele, F., De Clippeleer, J., Syryn, E., Goiris, K., De Cooman, L. and Aerts, G., Flavour instability of pale lager beers: determination of analytical markers in relation to sensory ageing. J. Inst. Brew., 2008, 114(2), 180-192.

39. Moir, M., Hops - A millennium review. J. Am. Soc. Brew. Chem., 2000, 58(4), 131-146.

40. Saison, D., De Schutter, D. P., Delvaux, F. and Delvaux, F. R., Optimisation of a complete method for the analysis of volatiles involved in the flavour stability of beer by solid-phase microextraction in combination with gas chromatography and mass spectrometry. J. Chromatogr. A, 2008, 1190, 342-349.

41. Saison, D., De Schutter, D. P., Uyttenhove, B., Delvaux, F. and Delvaux, F. R., Contribution of staling compounds to the aged flavour of lager beer by studying their flavour thresholds. Food Chem., 2009, 114, 1206-1215.

42. Stephan, A., Kusche, M. and Stettner, G., Influence of malt quality on the generation of odour-active Strecker aldehydes during beer aging. Proceedings of the European Brewery Convention Congress, Venice, 2007, Fachverlag Hans Carl: Nürnberg, Germany, CD ROM 2007, Contribution 99.

43. Syryn, E., Malfliet, S., Goiris, K., Van Opstaele, F., De Rouck, G., De Cooman, L., and Aerts, G., An integrated analytical-sensorial methodology for adequate evaluation of the flavour stability of Pilsner beer. Proceedings of the European Brewery Convention Congress, Venice, 2007, Fachverlag Hans Carl: Nürnberg, Germany, CD ROM 2007, Contribution 31.

44. Takashio, M. and Shinotsuka, K. Preventive production of beer against oxidation - Recent advances in brewing technology. Food Sci. Technol. Int. Tokyo, 1998, 4(3), 169-177.

45. Vanderhaegen, B., Neven, H., Verachtert, H. and Derdelinckx, G., The chemistry of beer aging - A critical review. Food Chem., 2006, 95, 357-381.
46. van Waesberghe J., Flavour stability starts with malt and in the brewhouse. Brauwelt Int., 2002, 20, 375-378.

47. van Waesberghe, J., Aerts, G. and De Cooman, L., Flavour stability starts with malt and compensations in the brewhouse for LOX and aldehydes in malt. Monograph 31 of the European Brewery Convention Symposium 'Flavour and Flavour Stability', Nancy, 2001, Fachverlag Hans Carl: Nürnberg, Germany, CD ROM 2001, Contribution 6.

48. VCF Volatile Compounds in Food: Database. L. M. Nijssen, C. A. Ingen-Visscher and J. J. H. van Donders, Eds. - Version 11.1.1 - Zeist (The Netherlands): TNO Quality of Life (19632010).

49. Verzele, M. and De Keukeleire, D., Chemistry and Analysis of Hop and Beer Bitter Acids. Elsevier: Amsterdam, 1991.

50. Vesely, P., Lusk, L., Basarova, G., Seabrooks, J. and Ryder, D., Analysis of aldehydes in beer using solid-phase microextraction with on-fibre derivatization and gas chromatography/mass spectrometry. J. Agric. Food Chem., 2003, 51, 6941-6944.

51. Wackerbauer, K. and Hardt, R., Radical reactions and flavour stability of beer. Brauwelt Int., 1997, 4, 320-327.

52. Walters, M. T., Heasman, A. P. and Hughes, P. S., Comparison of (+)-catechin and ferulic acid as natural antioxidants and their impact on beer flavor stability. Part 2: Extended storage trials. $J$. Am. Soc. Brew. Chem., 1997, 55(3), 91-98.

53. Wang, P. S. and Siebert, K. J., Determination of trans-2-nonenal in beer. Tech. Q. Master Brew. Assoc. Am., 1974, 11, 110-117.

54. Williams, R. S. and Wagner, H. P., Contribution of hop bitter substances to beer staling mechanisms. J. Am. Soc. Brew. Chem., 1979, 37, 13-19.

55. Yasui, T., Matsuura, C., Hori, T., Ogawa, Y. and Ohkochi, M., Importance of raw materials and the wort production process on trans-2-nonenal formation in beer. Monograph 31 of the European Brewery Convention Symposium 'Flavour and Flavour Stability', Nancy, 2001, Fachverlag Hans Carl: Nürnberg, Germany, CD ROM 2001, Contribution 8.

(Manuscript accepted for publication November 2010) 